B O N N E V I L L E P O W E R A D M I N I S T R A T I O Summary of Temperature Data Collected to Improve Emergence Timing Estimates for Chum and Fall Chinook Salmon in the Lower Columbia River

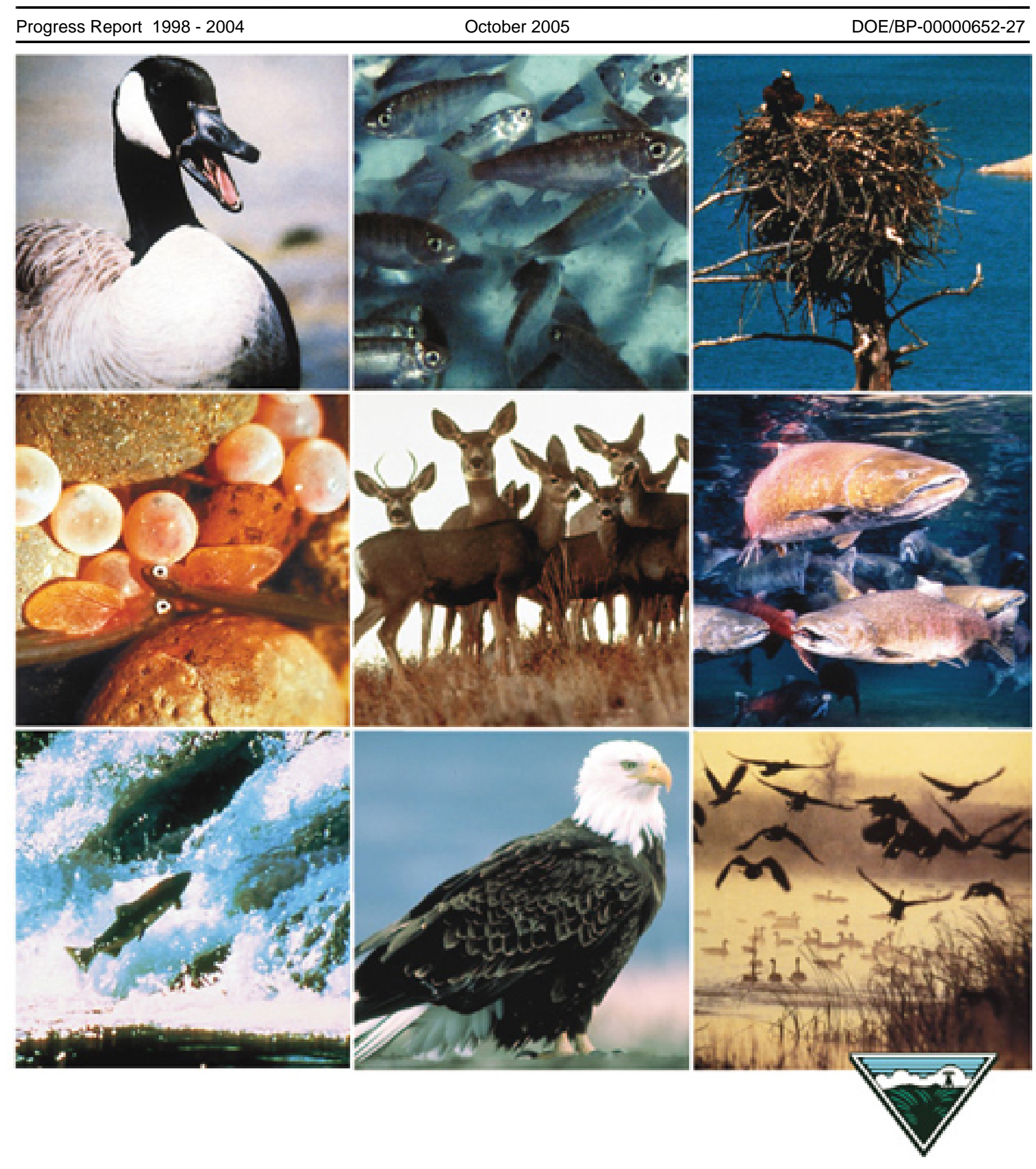


This Document should be cited as follows:

Arntzen, E., D. Geist, T. Hanrahan, K. McGrath, S. Thorsten, "Summary of Temperature Data Collected to Improve Emergence Timing Estimates for Chum and Fall Chinook Salmon in the Lower Columbia River", 1998-2004 Progress Report, Project No. 199900301, 33 electronic pages, (BPA Report DOE/BP-00000652-27)

\author{
Bonneville Power Administration \\ P.O. Box 3621 \\ Portland, OR 97208
}

This report was funded by the Bonneville Power Administration (BPA), U.S. Department of Energy, as part of BPA's program to protect, mitigate, and enhance fish and wildlife affected by the development and operation of hydroelectric facilities on the Columbia River and its tributaries. The views in this report are the author's and do not necessarily represent the views of BPA. 


\title{
Summary of Temperature Data Collected to Improve Emergence Timing Estimates for Chum and Fall Chinook Salmon in the Lower Columbia River
}

Progress Report

FY 1999 - 2004

\author{
Prepared by: \\ E. V. Arntzen \\ D. R. Geist \\ T. P. Hanrahan \\ K. E. McGrath \\ S. L. Thorsten \\ Pacific Northwest National Laboratory \\ Richland, WA 99352
}

\author{
Prepared for: \\ United States Department of Energy \\ Bonneville Power Administration \\ Division of Fish and Wildlife \\ P.O. Box 3621 \\ Portland, OR 97208 \\ Project No. 1999-00301 \\ Contract No. 652-0016
}

September 2005 


\section{Executive Summary}

From 1999 through 2004, Pacific Northwest National Laboratory collected temperature data from within chum and fall Chinook salmon spawning gravels and the overlying river at 21 locations in the Ives Island area approximately $5 \mathrm{~km}$ downstream from Bonneville Dam. Sample locations included areas where riverbed temperatures were elevated, potentially influencing alevin development and emergence timing. The study objectives were to 1 ) collect riverbed and river temperature data each year from the onset of spawning (October) to the end of emergence (June) and 2) provide those data in-season to fisheries management agencies to assist with fall Chinook and chum salmon emergence timing estimates.

Three systems were used over the life of the study. The first consisted of temperature sensors deployed inside piezometers that were screened to the riverbed or the river within chum and fall Chinook salmon spawning areas. These sensors required direct access by staff to download data and were difficult to recover during high river discharge. The second system consisted of a similar arrangement but with a wire connecting the thermistor to a data logger attached to a buoy at the water surface. This system allowed for data retrieval at high river discharge but proved relatively unreliable. The third system consisted of temperature sensors installed in piezometers such that real-time data could be downloaded remotely via radio telemetry. After being downloaded, data were posted hourly on the Internet. Several times during the emergence season of each year, temperature data were downloaded manually and provided to management agencies. During 2003 and 2004, the real-time data were made available on the Internet to assist with emergence timing estimates.

Examination of temperature data reveals several important patterns. Piezometer sites differ in the direction of vertical flow between surface and subsurface water. Bed temperatures in upwelling areas are more stable during salmon spawning and incubation than they are in downwelling areas. Bed temperatures in downwelling areas generally reflect river temperatures. Chum and fall Chinook salmon spawning is spatially segregated, with chum salmon in upwelling areas and fall Chinook salmon in downwelling areas. Although these general patterns remain similar among the years during which data were collected, differences also exist that are dependent on interannual flow characteristics. 


\section{Acknowledgments}

Corey Duberstein, Fenton Khan, Geoff McMichael, Jennifer Panther, Nathan Phillips, Scott Titzler, Ian Welch (Pacific Northwest National Laboratory), James Bernhard, Traci Degerman, Todd Newsome, Brett Nine, John Nugent, Michael Nugent, and Miguel Vilchez assisted piezometer installation, temperature data retrieval, and real-time data system installation. Gregg Gustafsen and Brett Walker (Instrumentation Northwest, Inc.) assisted with the design and installation of the real-time data system. 


\section{Contents}

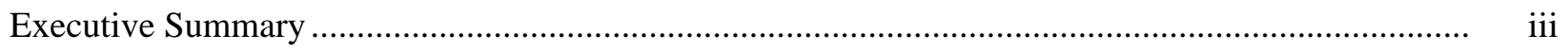

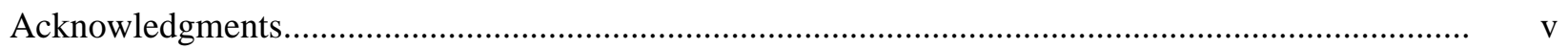

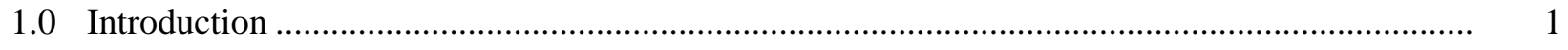

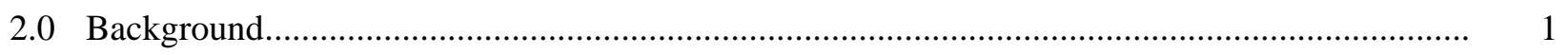

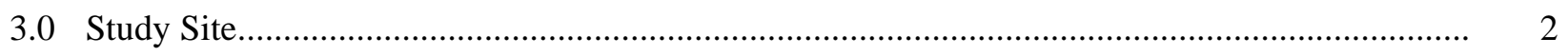

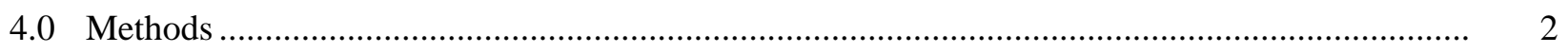

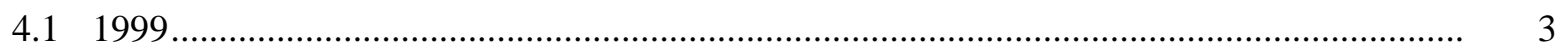

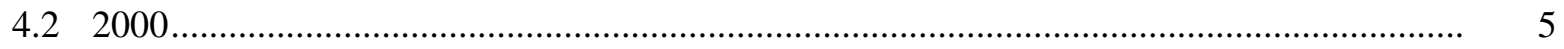

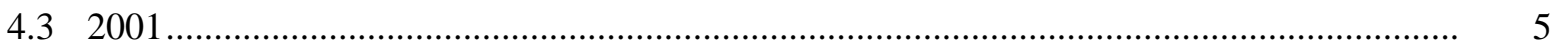

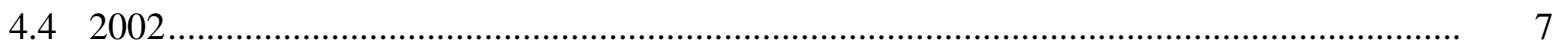

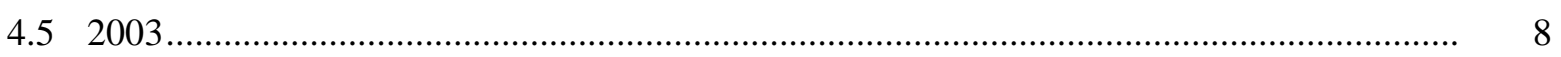

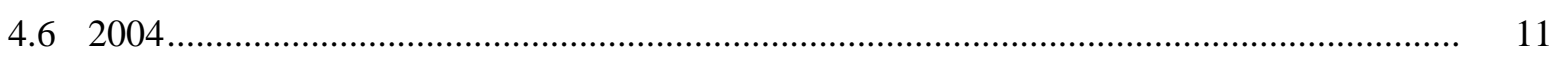

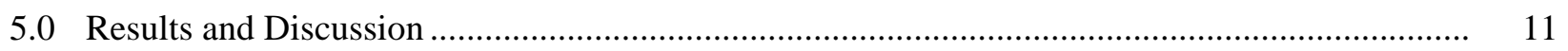

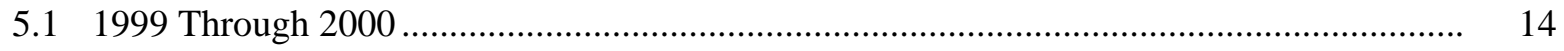

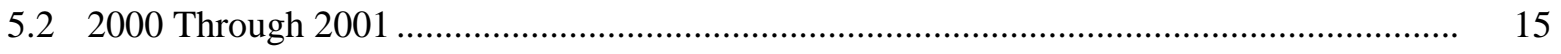

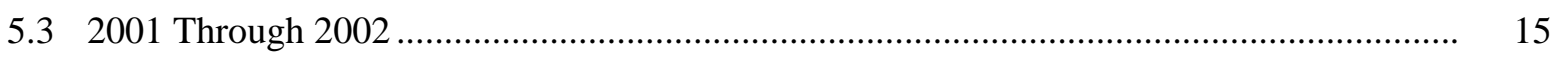

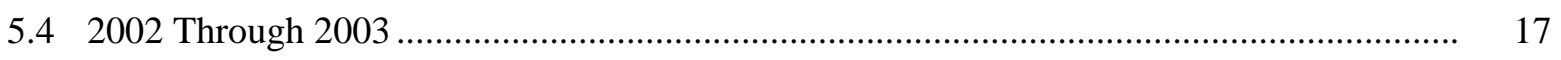

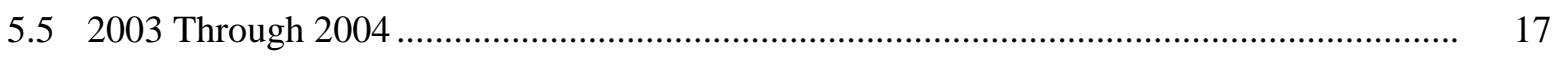

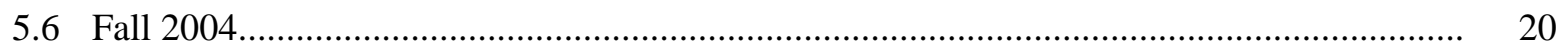

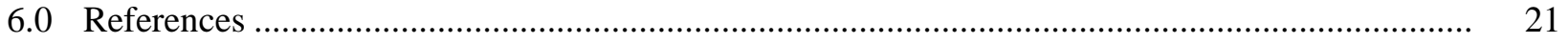

Appendix A - Temperature Sensor Location Information ............................................................. A.1

Appendix B - Summary of Temperature Data Collected Downstream from Bonneville Dam in the Ives Island Area by Pacific Northwest National Laboratory, 1999-2004 ........... B. B.1

Appendix C - Temperature Data Compendium ..................................................................... C.1 


\section{Figures}

1 Study Focus: Fall Chinook and Chum Salmon Spawning Areas Downstream from

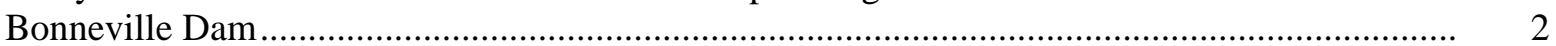

$2 \quad$ Locations of Piezometers Installed During 1999..................................................................

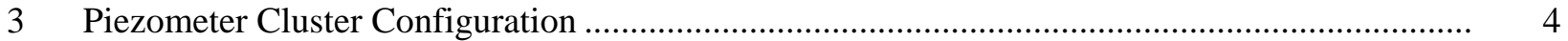

4 Piezometer and its Installation Using Drive Rod and Pneumatic Hammer ................................ 5

5 Configuration of Buoyed River and Riverbed Temperature Sampling System ........................... 6

$6 \quad$ Locations of Piezometers Installed During 2001..................................................................

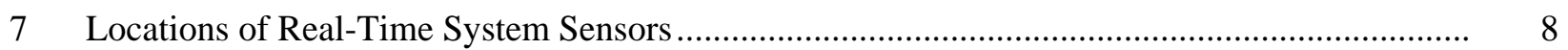

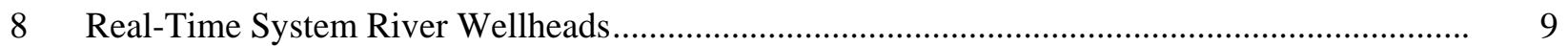

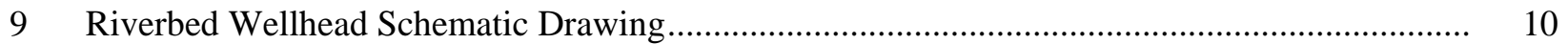

10 Columbia River Cross Section from A to A’ Relative to Water Level at Approximately $13 \mathrm{ft}$ Bonneville Tailwater Elevation and the Ordinary High Water Line..................................... 11

11 Chum and Fall Chinook Spawning Locations Relative to Temperature Data Collection

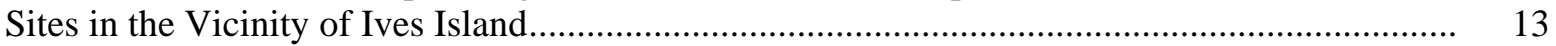

12 Bed Temperature Collected During 1999 through 2000 Within Chum and Fall Chinook

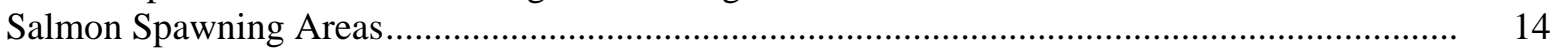

13 Bed Temperature Collected During 2000 through 2001 Within Chum and Fall Chinook

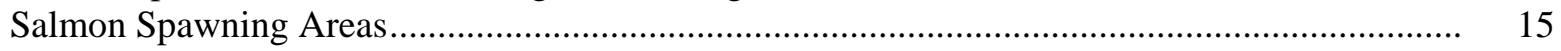

14 River and Riverbed Temperature, 2001 through 2002 ........................................................... 16

15 River and Riverbed Temperature, 2002 through 2003 ................................................................. 18

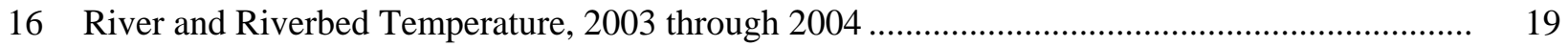

17 River and Riverbed Temperature During the Spawning Season, October 1 Through December 31, 2004, for Real-Time Sensors T1LB, T2LB, and T2MC

\section{Tables}

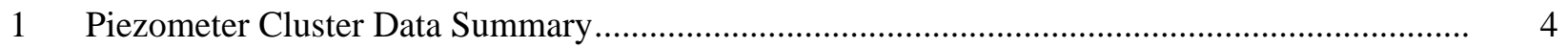

2 Availability of Complete Data Sets for the Spawning and Incubation Period ............................ 12 


\subsection{Introduction}

From 1999 to 2005, the Bonneville Power Administration (BPA) has funded a study to quantify fall Chinook and chum salmon spawning downstream from Bonneville Dam; the timing of spawning, emergence, and rearing; characteristics of their spawning habitat; and flows necessary to ensure their long-term survival.

The primary location of this study is near Ives Island, an off-channel spawning area approximately $5 \mathrm{~km}$ downstream from Bonneville Dam. During 1999, researchers from Pacific Northwest National Laboratory (PNNL) ${ }^{1}$ identified areas where relatively warm subsurface water upwelled through chum spawning gravels in the Ives Island spawning complex (Geist et al. 2002).

Since 1999, PNNL has monitored river and bed temperatures in the Ives Island channel to assist the Oregon Department of Fish and Wildlife (ODFW) with emergence timing predictions for fall Chinook and chum salmon. This report presents a chronological summary of the methods used and data obtained by PNNL from 1999 through 2004 to improve emergence timing estimates for Chinook and chum salmon. A digital appendix containing all temperature data collected for emergence timing estimation is included in this report. Data analysis is not included in this report; subsequent reports will examine relationships between hydrosystem operation and riverbed temperatures.

\subsection{Background}

Although historically abundant, run sizes of chum salmon and fall Chinook salmon to the Columbia River had decreased dramatically by the 1950s as a result of habitat degradation, water diversion, overharvest, and artificial propagation (National Marine Fisheries Service 1998). Populations of both species spawning downstream from Bonneville Dam are currently listed as threatened under the Endangered Species Act (National Marine Fisheries Service 1999).

Spawning surveys conducted at Ives Island since 1998 indicated that chum salmon and fall Chinook salmon spawn in spatially distinct clusters (U.S. Fish and Wildlife Service [USFWS] and ODFW, unpublished data). This clustering suggests that these species may select specific, and different, spawning habitat features within the study area (Geist and Dauble 1998). Understanding the spatial distribution of subsurface temperature variation is critical to accurate estimation of emergence timing and establishment of meaningful minimum flows for the protection of spawning habitat in this area.

\footnotetext{
${ }^{1}$ Pacific Northwest National Laboratory is operated by Battelle for the U.S. Department of Energy.
} 


\subsection{Study Site}

Data were collected from spawning areas downstream of the mouth of Hamilton Creek between Ives Island and the USFWS Pierce Wildlife Refuge and in an area between Ives and Pierce Islands (Figure 1). The location coordinates of all sensors used to collect data presented in this document are included in Appendix A.

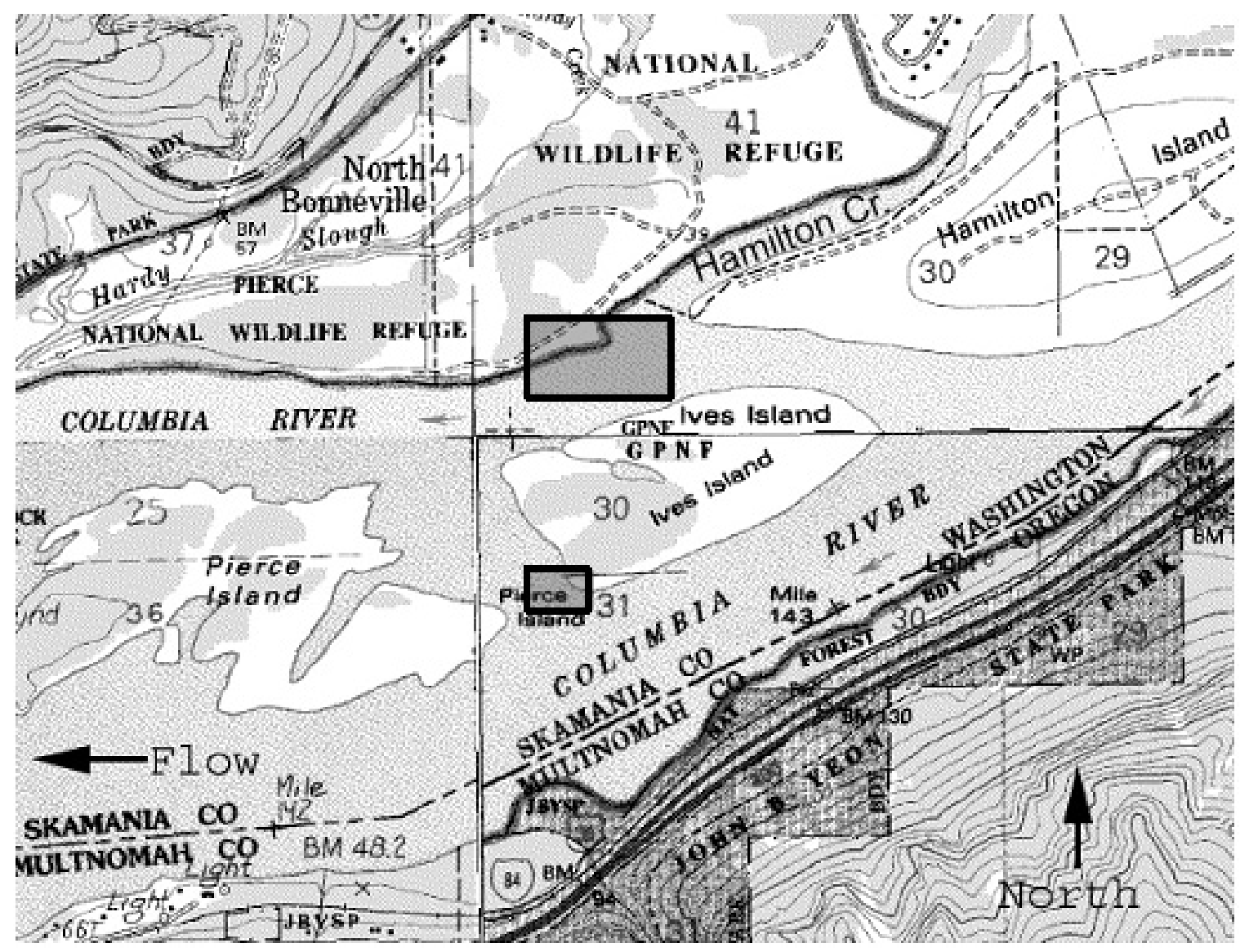

Figure 1. Study Focus: Fall Chinook and Chum Salmon Spawning Areas (shaded boxes) Downstream from Bonneville Dam

\subsection{Methods}

The various types of sensors and deployment techniques used each year of the study are described in this section. Summaries of the methods used during each year also are included. 


\section{$4.1 \quad 1999$}

Temperature sensors were deployed at various depths below the riverbed surface within fall Chinook and chum salmon spawning areas. Sensors were also deployed within non-spawning locations for comparison. Work was concentrated in the spawning areas downstream from the mouth of Hamilton Creek in the vicinity of Ives Island (Figure 1).

On October 20, 1999, eight piezometer clusters were established (Figure 2). Each cluster site was classified as either spawning or non-spawning. Nineteen piezometers were installed, 8 in non-spawning areas and 11 in spawning areas. The distinction between spawning and non-spawning areas was made based on existing spawning distributions data (USFWS and ODFW, unpublished data).

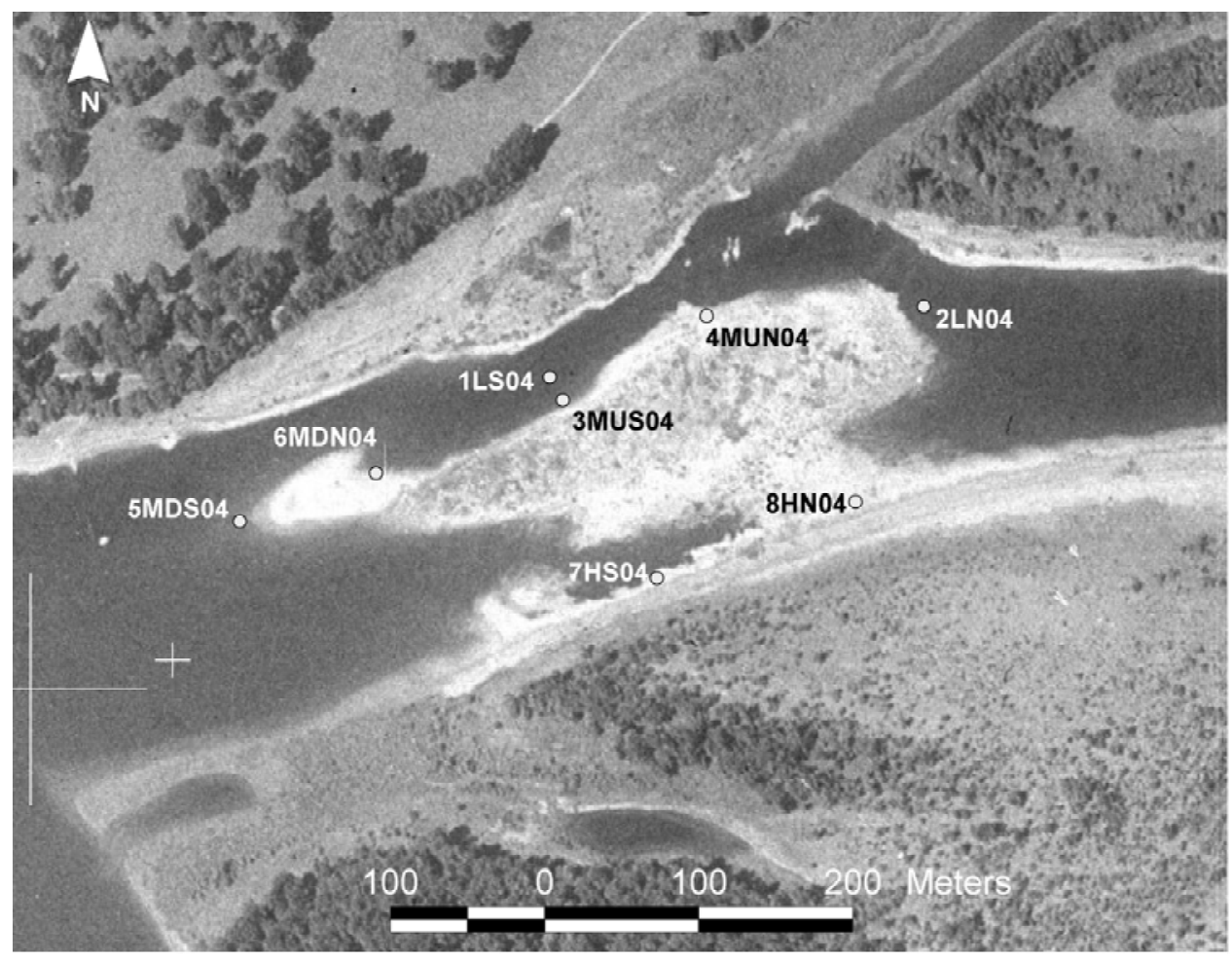

Figure 2. Locations of Piezometers Installed During 1999 (circles). The labeling scheme provides the cluster number (1 through 8), discharge range ( $\mathrm{L}=125 \mathrm{kcfs}, \mathrm{M}=145 \mathrm{kcfs}, \mathrm{H}=165 \mathrm{kcfs}$ ), location ( $\mathrm{U}=$ upriver; $\mathrm{D}=$ downriver), and piezometer length $(3,4,5 \mathrm{ft}$ ) for each site.

Cluster locations in both spawning and non-spawning habitat were established at several different vertical elevations to allow sampling over a wide range of Bonneville Dam discharges, including three targeted flow bands (where kcfs denotes thousand cubic feet per second): 125 to $140 \mathrm{kcfs}$ (low), 140 to $150 \mathrm{kcfs}$ (medium), and 150 to $160 \mathrm{kcfs}$ (high). Two clusters were placed in the low, four clusters in the medium, and two clusters in the high flow bands. At each cluster, we attempted to install piezometers to approximate depths of $0.9,1.2$, and $1.5 \mathrm{~m}$, respectively, below the riverbed. Five piezometers were broken during installation, leaving some clusters with only two piezometers (Table 1). At each cluster, piezometers were arranged in a triangular pattern within approximately $1 \mathrm{~m}$ of each other (Figure 3). Coordinate location data for each cluster was recorded with a Trimble ProXL GPS receiver. These data were post-processed with correction files from the Portland State University Geology Department 
Community Base Station. After post-processing, the coordinate location accuracy is $\pm 1.0 \mathrm{~m}$. The location coordinates for 1.2-m piezometers from each cluster are included in Appendix A.

Table 1. Piezometer Cluster Data Summary

\begin{tabular}{||c|c|c|c|c|c||}
\hline \multirow{2}{*}{ Cluster } & \multirow{2}{*}{$\begin{array}{c}\text { Discharge } \\
\text { Range }\end{array}$} & \multirow{2}{*}{$\begin{array}{c}\text { Habitat } \\
\text { Designation }\end{array}$} & \multicolumn{3}{|c||}{ Piezometer Screen Depth (cm) } \\
\cline { 4 - 6 } & & $0.9 \mathrm{~m}$ & $1.2 \mathrm{~m}$ & $1.5 \mathrm{~m}$ \\
\hline \hline 1 & Low & Spawning & 40.0 & 72.0 & 98.5 \\
\hline 2 & Low & Non-spawning & 32.2 & 64.0 & (a) \\
\hline 3 & Medium & Spawning & 42.2 & 70.0 & (a) \\
\hline 4 & Medium & Non-spawning & 42.4 & 71.2 & (a) \\
\hline 5 & Medium & Spawning & 41.9 & 72.2 & 103.7 \\
\hline 6 & Medium & Non-spawning & 41.1 & 71.1 & (a) \\
\hline 7 & High & Spawning & 41.3 & 67.4 & 98.8 \\
\hline 8 & High & Non-spawning & 37.4 & 67.3 & (a) \\
\hline (a) Piezometer broken during installation. See text for description of discharge ranges. \\
\hline
\end{tabular}

$1.2 \mathrm{~m}$

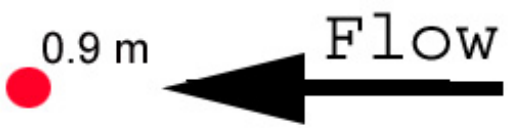

$1.5 \mathrm{~m}$

Figure 3. Piezometer Cluster Configuration

Piezometer screens were constructed of slotted stainless steel Johnson screen (0.038-cm slot size) with a 31.0-cm screened interval and a 3.2-cm inside diameter (Figure 4a). The screen was welded on one end to a 12-cm drive point and on the other end to a variable-length section of galvanized steel pipe (3.2 cm inner diameter) threaded on top. Piezometers were installed by inserting a solid steel drive-rod into the piezometer and pounding the rod with a post pounder or pneumatic hammer until the desired depth below the riverbed surface was achieved (Geist et al. 1998; Figure 4b). Once piezometers were in place, the internal drive-rod was removed and the piezometer was developed by removing fine sediment (smaller than $0.38 \mathrm{~mm}$ ) with a hand pump.

Temperature-recording data loggers (Onset Optic Stowaway) were installed in the 1.2-m piezometer at each cluster. The depth below the riverbed where the temperature measurement was recorded ranged from 64 to $72 \mathrm{~cm}$ (Table 1). Temperature data were collected hourly beginning on October 21, 1999. Each data logger was certified to National Institute of Standards and Technology criteria with an accuracy of $\pm 0.2^{\circ} \mathrm{C}$. 


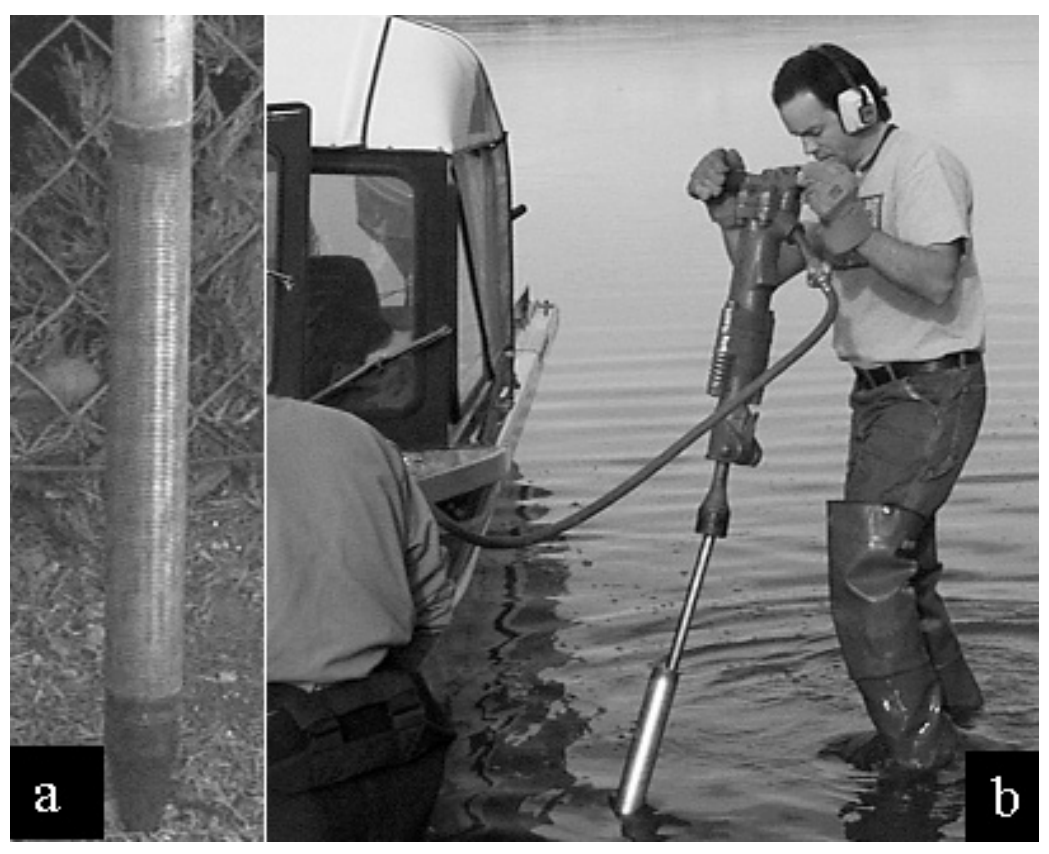

Figure 4. Piezometer (a) and its Installation Using Drive Rod and Pneumatic Hammer (b)

\subsection{0}

On November 6 and 7, 2000, temperature sensors attached to buoys were deployed in the 1.2-m piezometers at clusters 1LS04, 4MUN04, and 7HS04. The buoy systems were designed to allow sampling at high river discharge so data could be provided to agencies earlier rather than after high spring flows had subsided. The buoys were spatially distributed to include spawning areas in low and high discharge ranges and a non-spawning area at medium discharge. To make room for the thermistors, Onset data loggers were removed from the 1.2-m piezometers where the buoys were installed. At Clusters 1 and 7, the Onset data loggers were moved into the 1.5-m piezometers. At Cluster 4, the 1.5-m piezometer was not installed; the 0.90 -m piezometer had filled with sand and was not usable, so the Onset data logger was removed. At all three clusters, thermistors were placed inside the 1.2-m piezometer with the temperature sensor at the top of the screen (Figure 5). A second thermistor was attached to the piezometer and deployed in the river adjacent to the riverbed to record river temperature. Thermistor wires were routed through approximately $12 \mathrm{~m}$ of polyethylene tubing that was zip-tied to approximately $3 \mathrm{~m}$ of $0.95-\mathrm{cm}$-diameter anchor chain and then to approximately $9 \mathrm{~m}$ of steel cable. The anchor chains were shackled to $30-\mathrm{kg}$ weights of scrap iron. The weights were deployed approximately $1.5 \mathrm{~m}$ upstream of the piezometer clusters, and cable ends were attached to mooring buoys. The polyethylene tubing was routed into a watertight canister attached to each buoy. Data loggers were attached to the wires inside each canister, allowing the data to be by wading or from the deck of a boat.

\section{$4.3 \quad 2001$}

On November 27 and 28, 2001, 14 additional piezometers were installed at the site to augment in-season temperature data provided to government agencies for emergence timing estimation and for other project purposes associated with groundwater/surface water interactions (Figure 6). Equipment and 
methods used in piezometer installation were similar to those in 2000. Piezometer locations were selected based on separate project activities that identified areas of warm upwelling water associated with chum spawning and established that bed and river temperatures maintained continuity for approximately $60 \mathrm{~m}$ in the direction of flow (Geist et al. 2002). Additional factors influencing piezometer location included the expected range of discharges from Bonneville Dam and the availability of sensors (see below). Transects T1, T2, and T3 were in chum spawning areas, and transects T4 and T5 were in fall Chinook salmon spawning areas. At locations T1 to T5, two piezometers were installed at the mid-channel location (MC), one screened to the riverbed (top of the screen $20 \mathrm{~cm}$ below the riverbed) and the other to the river. A Solinst Model 3001 LT levelogger was deployed in each MC piezometer to record temperature differences between bed and river. All data loggers were installed with the sensors at the middle of the screen (30 cm below the riverbed). Solinst LT data loggers record temperature differences with an accuracy of $\pm 0.1^{\circ} \mathrm{C}$.

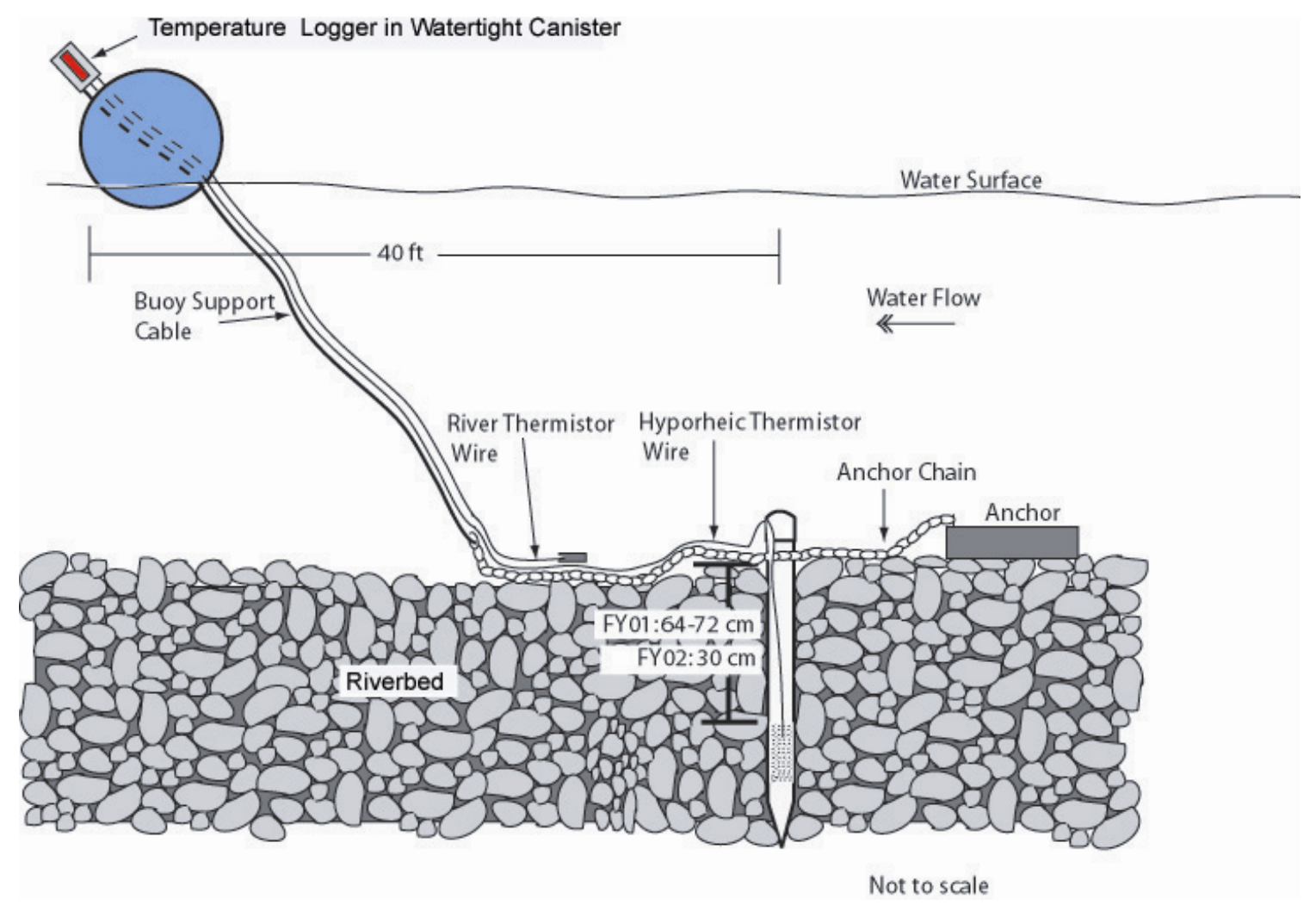

Figure 5. Configuration of Buoyed River and Riverbed Temperature Sampling System

We randomly selected additional piezometers to instrument with temperature data loggers because an insufficient number were available to instrument all piezometers installed in 2001. The right bank (RB) locations on transects T1, T2, and T4 were instrumented with Onset data loggers. At T3, the locations on the RB and left bank (LB) were instrumented, and at T5 a second piezometer on the RB was instrumented using Onset data loggers. One piezometer at T6 was instrumented similarly. At each location, a data logger was placed in the riverbed piezometer $30 \mathrm{~cm}$ below bed and also in a polyvinyl chloride (PVC) sleeve screened to the river and attached to the piezometer. The Onset data loggers were similar to those installed during 1999 and 2000. 


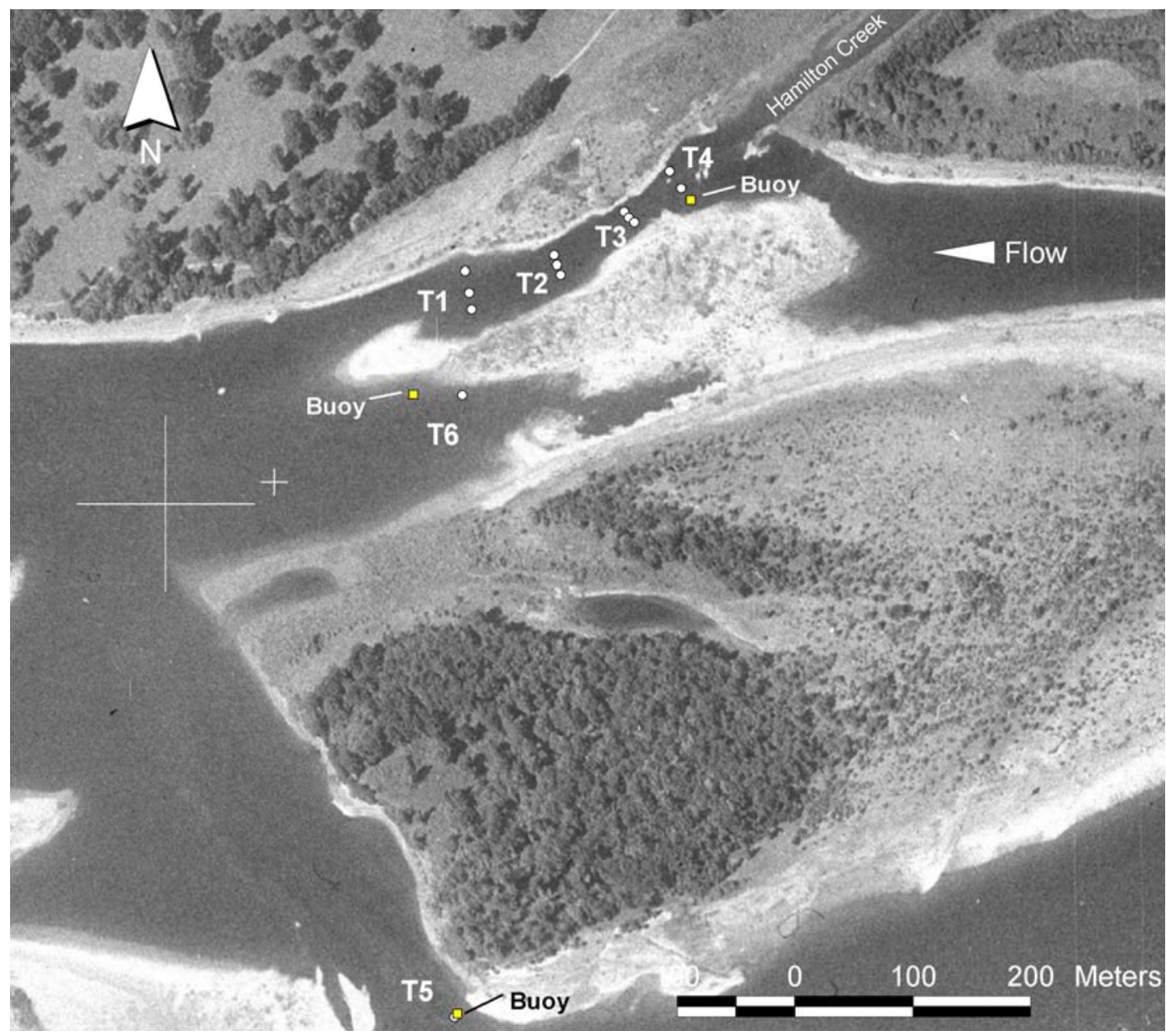

Figure 6. Locations of Piezometers Installed During 2001 (white circles). Yellow squares show piezometers that were later equipped with buoy systems to access bed and river sensors at high discharges.

At the same time that these piezometers were installed, three additional piezometers were installed for future deployment of buoy systems, on transects T4 (LB), T5, and T6. The 2001 buoy piezometers were installed with screen depths of $30 \mathrm{~cm}$ to reflect egg pocket conditions. The buoy systems successfully produced temperature data during various time periods while they were deployed. However, by spring 2001, all the buoy systems installed in 2000 had been removed due to problems with water infiltration through the polyethylene tubing or vandalism.

\subsection{2}

Buoys were deployed at T4LB on January 25, 2002, and at T5 and T6 on February 13, 2002. These buoy systems were similar to those installed in 2000, except that sensor depth was reduced from 64 to $30 \mathrm{~cm}$ below the riverbed to more accurately reflect egg pocket depth. The buoy systems were used to provide in-season emergence timing temperature data to the agencies during winter and spring 2002. Other sensors installed during 2000 and 2001 were maintained and downloaded, and temperature data were archived, when field conditions allowed access. 


\section{$4.5 \quad 2003$}

On September 6 through 9, 2003, a real-time temperature collection system was deployed in the north channel at the study site to provide real-time river and riverbed temperature data within chum salmon spawning areas. One riverbed sensor and one river sensor were installed at T1LB, T2LB, and T2MC (Figures 7 and 8). These sites were selected because transects T1 and T2 were associated with chum spawning, and habitat modeling suggested that although high-quality habitat was available throughout the channel at low flows (104 kcfs), at higher flows (125 to $150 \mathrm{kcfs}$ ) spawning habitat was located primarily along the left bank (Garland et al. 2003).

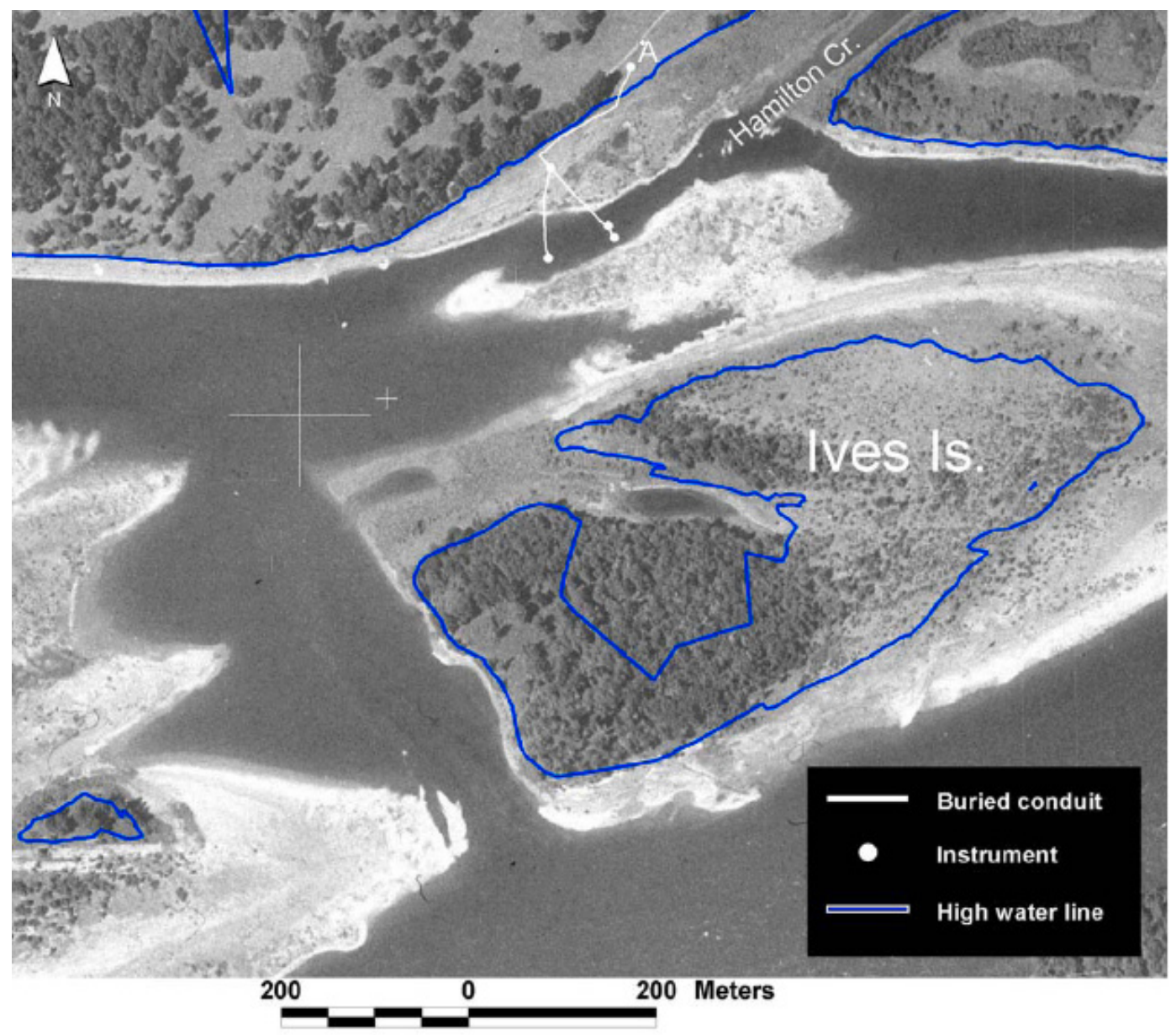

Figure 7. Locations of Real-Time System Sensors (white circles). White lines show the locations of buried cables. The telemetry station is above the high water line at point A.

At all sites, 5-cm well points were installed and used to anchor constructed wellheads. The river piezometers did not have screens, and contact between the sensor and the river was made using a 15-cm PVC wellhead with a screen open only to the surface water column (Figure 8). 


\section{River Wellhead Deployment}

River Wellhead
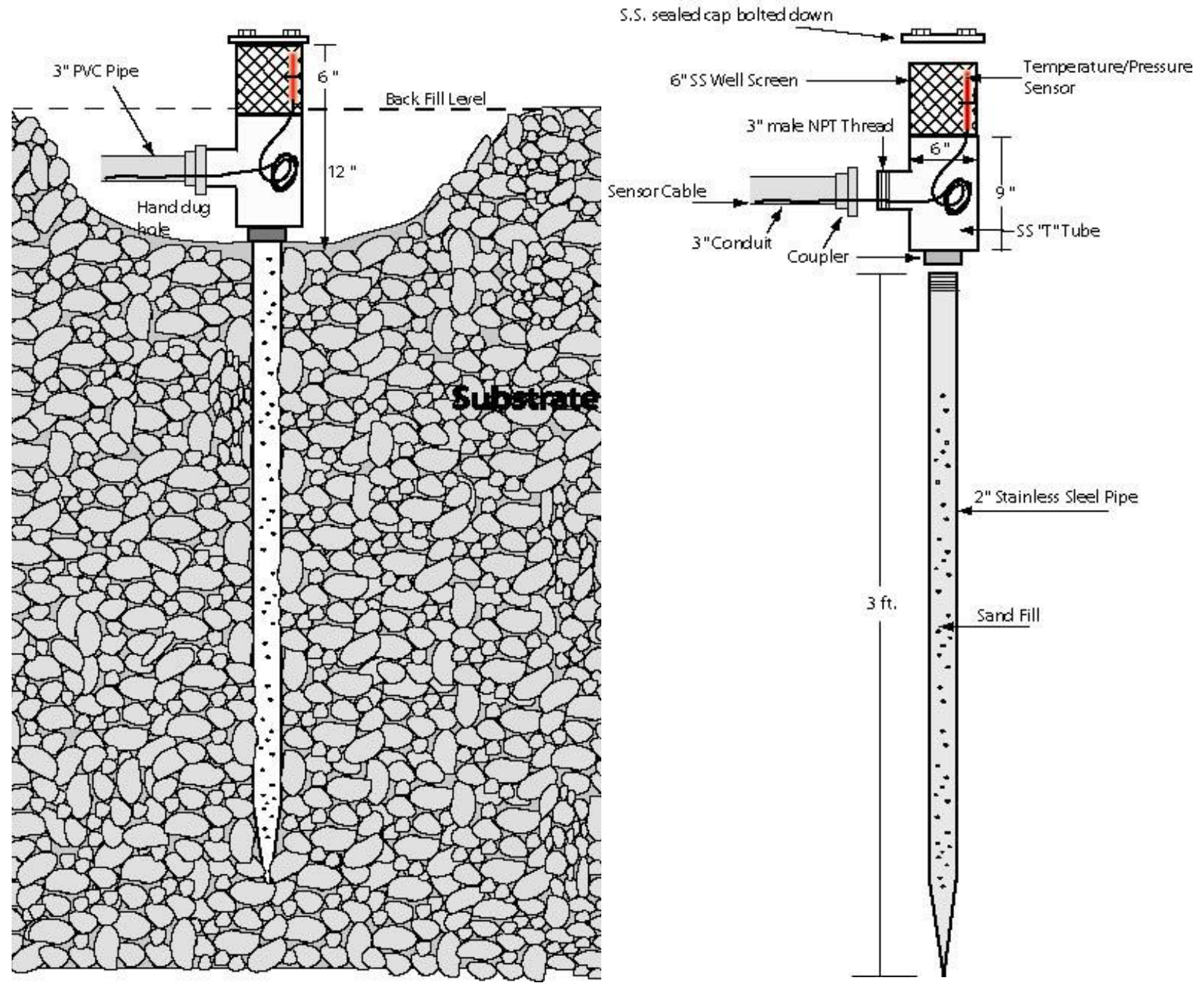

Figure 8. Real-Time System River Wellheads

The sensors monitoring bed temperatures were anchored by similar 5-cm well points, with 30-cm screened intervals near their tops. Piezometers were installed using methods similar to those for previous years' piezometer installations. The riverbed wellheads were deployed with the tops of their screens $58 \mathrm{~cm}$ below the riverbed (Figure 9).

Rubber stoppers were used to prevent the movement of water from the riverbed wellhead into the screened interval and to prevent water movement from the conduit and the piezometer into the river wellhead. River and riverbed piezometers were filled with sand to help minimize artificially induced temperature gradients due to convection.

Six Model PT2X sensors (Instrumentation Northwest, Inc.) were used for the real-time system, with each sensor recording absolute pressure and temperature. One additional barometric sensor was installed 
on the telemetry tower to record atmospheric pressure and temperature. The PT2X sensors were not vented, minimizing problems that can occur with desiccants under humid conditions and reducing cable expense and maintenance frequency. PT2X sensor temperature accuracy is $\pm 0.75^{\circ} \mathrm{C}$ with a resolution of $0.1^{\circ} \mathrm{C}$. Sensors were connected to a telemetry tower via buried cables (Figures 7 and 10 ). The telemetry system uses solar-powered line-of-sight radio and transmits to a station in the town of North Bonneville approximately $2.4 \mathrm{~km}$ from the study site. The data are queried hourly and posted to a file transfer protocol (FTP) server maintained by Instrumentation Northwest, Inc. (INW). The Fish Passage Center (FPC) retrieves the data from the INW FTP site and posts them at http://www.fpc.org/ivesisland/ives_island_home.html.

\section{Riverbed Wellhead Deployment}

\section{Riverbed Wellhead}

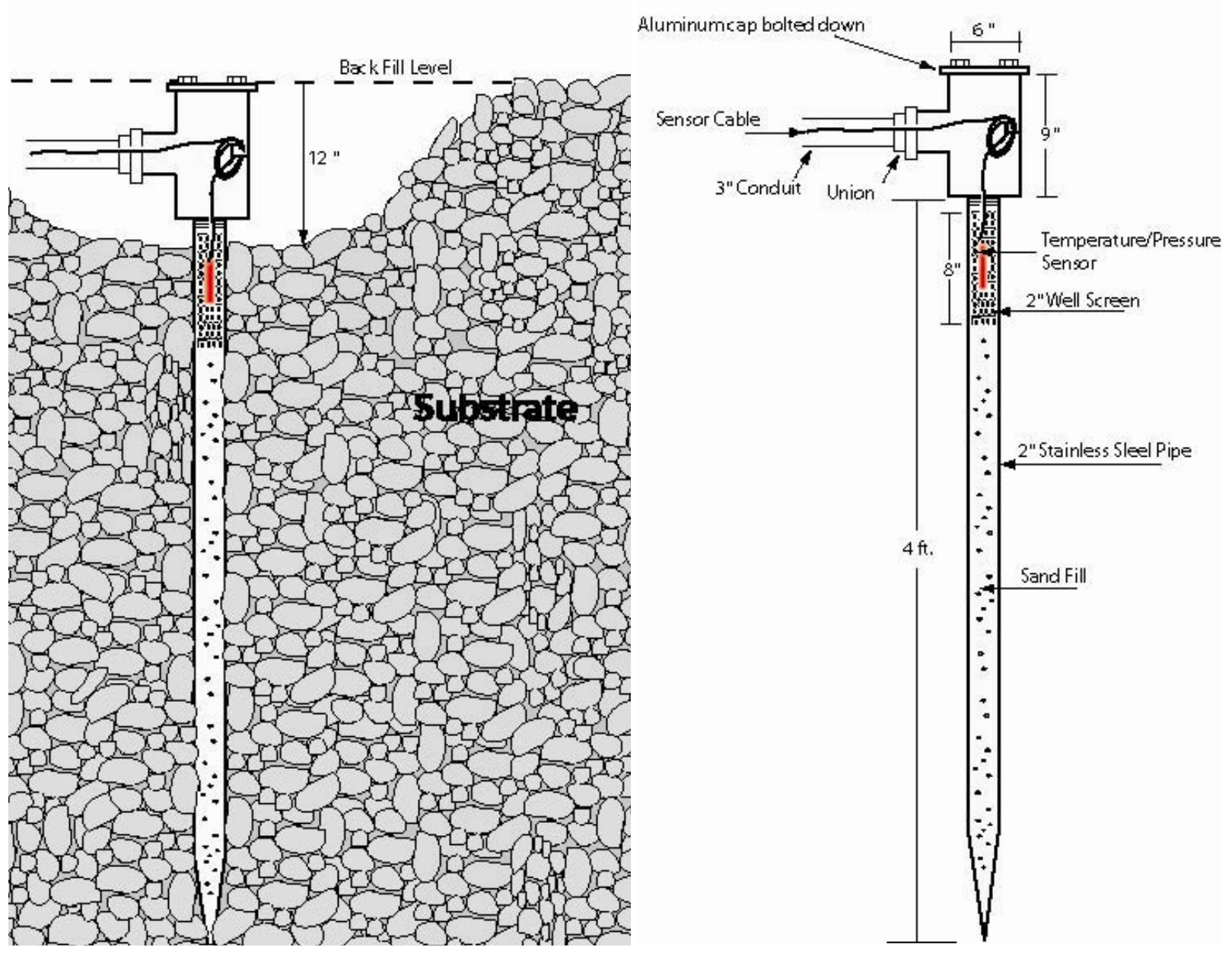

Figure 9. Riverbed Wellhead Schematic Drawing 


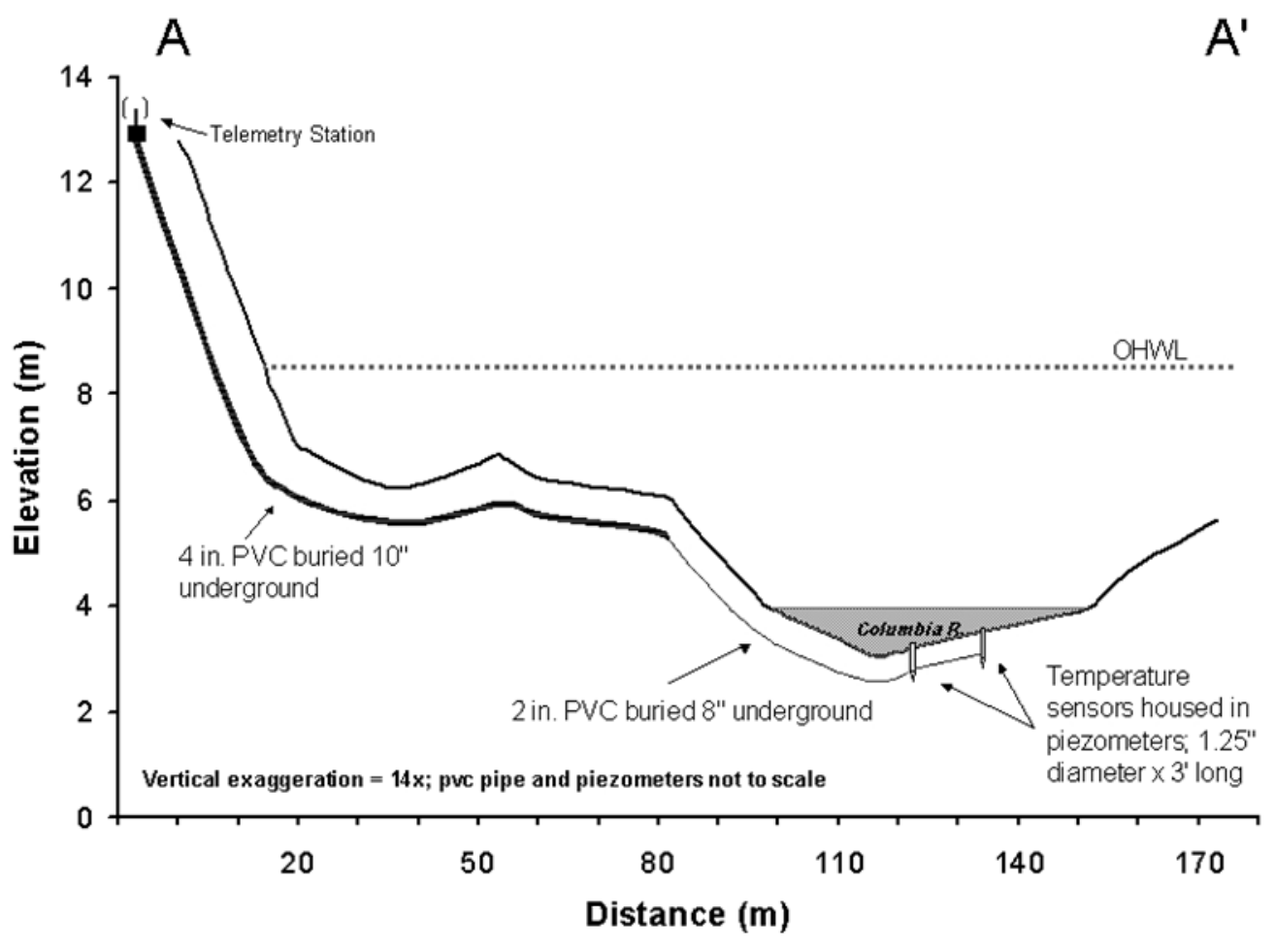

Figure 10. Columbia River Cross Section from A to A' (see Figure 7) Relative to Water Level at Approximately $13 \mathrm{ft}$ Bonneville Tailwater Elevation and the Ordinary High Water Line

\section{$4.6 \quad 2004$}

Temperature data were downloaded from sensors deployed during previous years. Additional Onset data loggers were deployed in piezometers adjacent to each real-time wellhead (T1LB, T2LB, and T2MC). Onset sensors were deployed 20 to $30 \mathrm{~cm}$ below the riverbed to collect temperature data at egg pocket depth and to calibrate temperature data collected from the deeper real-time systems.

\subsection{Results and Discussion}

In this section, we present representative data plots, summaries of data availability, and general data trends to facilitate use by others. The time period during which bed and river data were successfully collected varied, as did the type of sensors used to collect the data. Data among sensor types are comparable, within the accuracy limits of the sensors. Location coordinates and sensor depths below the riverbed are included for each location where temperature data were collected (Appendix A). Temperature data availability is summarized in Appendix B. All temperature data collected from 1999 through 2004 are presented in Appendix C.

During 1999 through 2004, riverbed and river water temperatures were provided to ODFW, the Washington Department of Fish and Wildlife, USFWS, and BPA to assist these agencies with chum and fall Chinook salmon emergence timing estimation. For this reason, we focus on data for which we have 
complete records during the spawning through emergence period (October 1 through June 30). Data available for this period are summarized in Table 2 and are discussed by year in Sections 5.1 through 5.6. We provide general comparisons of data between riverbed and river sensors and between sites used by chum and fall Chinook salmon. Data for this period, and only data from spawning locations, were used in temperature comparisons presented here. Comparative statistics are provided as general descriptions; more rigorous analyses should be conducted by (and are the responsibility of) data users.

Table 2. Availability of Complete Data Sets for the Spawning and Incubation Period (October 1 through June 30)

\begin{tabular}{|c|c|c|c|c|c|c|c|}
\hline \multirow[b]{2}{*}{ Piezometer } & \multirow[b]{2}{*}{ Use } & \multicolumn{6}{|c|}{ Year } \\
\hline & & $1999-2000$ & $2000-2001$ & 2001-2002 & $2002-2003$ & 2003-2004 & Fall 2004 \\
\hline 1LS04 & $\mathrm{C}$ & $\mathrm{B}^{(\mathrm{a})}$ & & & & & \\
\hline 2LN04 & $\mathrm{N}$ & $\mathrm{B}^{(\mathrm{b})}$ & $\mathrm{B}$ & $B$ & & & \\
\hline 3MUS04 & $\mathrm{C}$ & $\mathrm{B}^{(\mathrm{b})}$ & B & B & B & & \\
\hline 4MUN04 & FC & $\mathrm{B}^{(\mathrm{b})}$ & & & & & \\
\hline 5MDS04 & $\mathrm{N}$ & $\mathrm{B}^{(\mathrm{b})}$ & B & B & B & & \\
\hline 6MDN04 & $\mathrm{N}$ & $\mathrm{B}^{(\mathrm{b})}$ & B & B & B & B & \\
\hline 7HS05 & $\mathrm{N}$ & & & B & & B & \\
\hline T1LB & $\mathrm{C}$ & & & & & $\mathrm{B}, \mathrm{R}^{(\mathrm{c})}$ & $\mathrm{B}, \mathrm{R}$ \\
\hline T1MC & $\mathrm{C}$ & & & $\mathrm{B}, \mathrm{R}^{(\mathrm{d})}$ & $\mathrm{B}, \mathrm{R}$ & $\mathrm{B}, \mathrm{R}$ & \\
\hline T1RB & $\mathrm{C}$ & & & & & B & \\
\hline T2LB & $\mathrm{C}$ & & & & & $\mathrm{B}, \mathrm{R}^{(\mathrm{c})}$ & $\mathrm{B}, \mathrm{R}$ \\
\hline T2MC & C & & & & & $\mathrm{B}, \mathrm{R}^{(\mathrm{c})}$ & $\mathrm{B}, \mathrm{R}$ \\
\hline T2RB & C & & & $\mathrm{B}, \mathrm{R}^{(\mathrm{d})}$ & & & \\
\hline T3LB & C,FC & & & $\mathrm{B}^{(\mathrm{d})}$ & & & \\
\hline T3MC & $\mathrm{C}, \mathrm{FC}$ & & & $\mathrm{R}^{(\mathrm{d})}$ & $\mathrm{R}$ & $\mathrm{B}, \mathrm{R}$ & \\
\hline T3RB & C,FC & & & & B & & \\
\hline T4MC & FC & & & $\mathrm{B}, \mathrm{R}^{(\mathrm{d})}$ & $\mathrm{B}, \mathrm{R}$ & $\mathrm{R}$ & \\
\hline T4RB & FC & & & & $\mathrm{B}, \mathrm{R}$ & $\mathrm{B}, \mathrm{R}$ & \\
\hline $\mathrm{T} 5$ & $\mathrm{C}, \mathrm{FC}$ & & & $\mathrm{B}, \mathrm{R}^{(\mathrm{d})}$ & & & \\
\hline $\begin{array}{l}\text { (a) Start dat } \\
\text { (b) Start dat } \\
\text { (c) Start dat } \\
\text { (d) Start dat } \\
\mathrm{B}=\text { Bed. } \\
\mathrm{C}=\text { Chum } \\
\mathrm{FC}=\text { Fall } \\
\mathrm{N}=\text { None. } \\
\mathrm{R}=\text { River }\end{array}$ & $\begin{array}{l}\text { Octobe } \\
\text { Novem } \\
\text { Novem } \\
\text { Octobe } \\
\\
\text { ok. }\end{array}$ & & & & & & \\
\hline
\end{tabular}

Piezometers were located in either chum or fall Chinook salmon spawning sites or in areas not used by either species (Figure 11). Spawning associations were based on visual comparison of ODFW spawning count data for 2000 through 2004 (ODFW, unpublished data) and piezometer locations within a 
geographic information system. Redd mapping efforts conducted since 1999 have demonstrated that several of our classifications at the time of equipment installation and as described in Section 4 were incorrect. Sites 1LS04 and 3MUS04 are associated with chum salmon spawning, 4MUN04 is associated with fall Chinook salmon spawning, and the remainder of the sites in this coding system are not associated with salmon spawning. Transects T1 and T2 are associated with chum spawning, transect T4 is associated with fall Chinook salmon spawning, and transect T3 is a region of spawning overlap between these species.

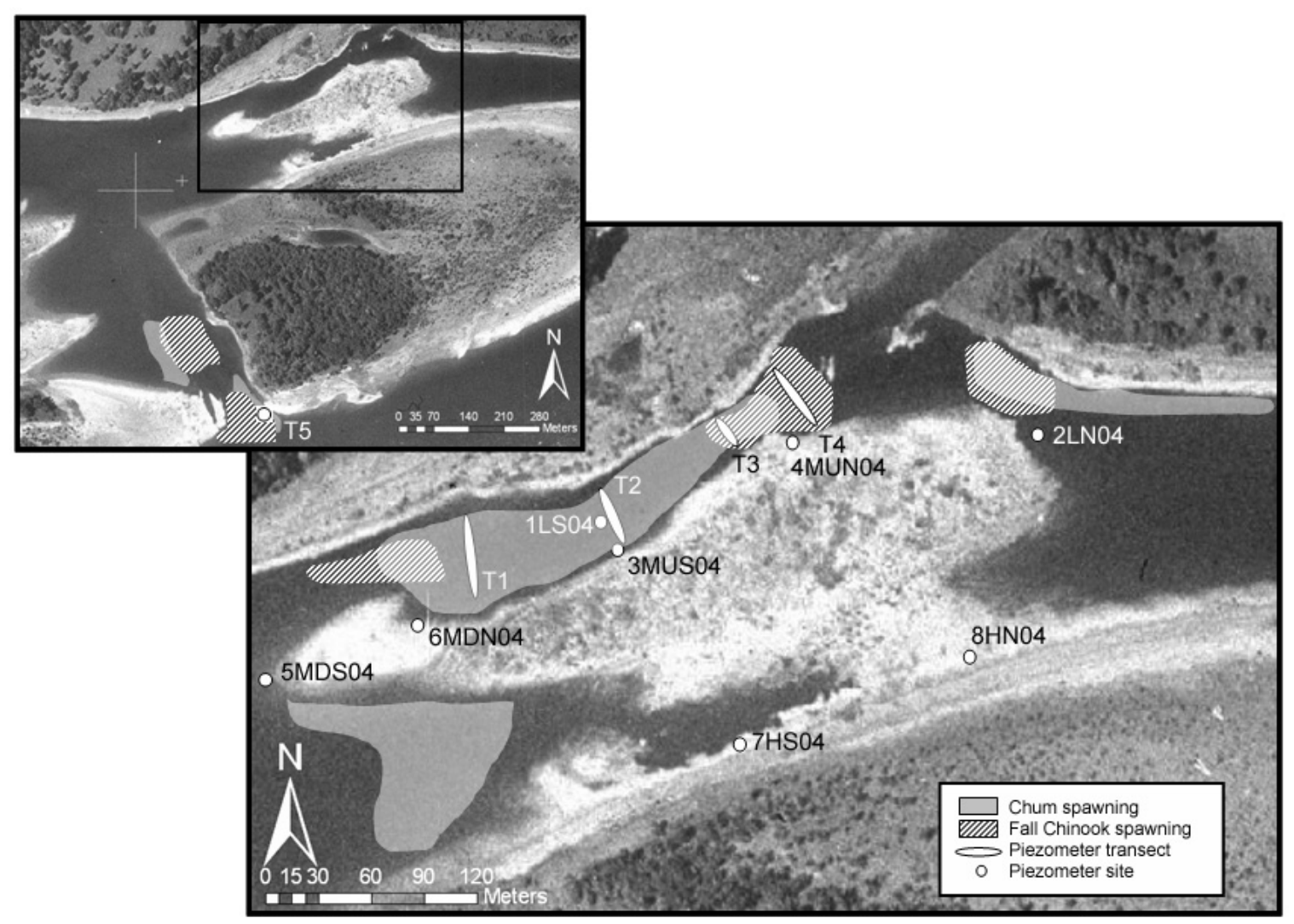

Figure 11. Chum and Fall Chinook Spawning Locations Relative to Temperature Data Collection Sites in the Vicinity of Ives Island

The availability of calendar year data sets varies by sensor type, location (bed versus river), and applicability to chum versus fall Chinook salmon. For 1999 through 2001, most of the temperature data we collected were from sensors deployed in the riverbed. At least one calendar year of data is available for five sites (2LN04, 3MUS04, 5DMS04, 6MDN04, 7HS05). Less than one year of data is available for four additional sites (1LS04, 1LS05, 4MUN04, 7HS04). River data are limited to two sites (1LS04, 4MUN04) and to periods of six months or less. Beginning in 2002, full-year data sets are available for more sites and include some sites with paired river and riverbed data. From 2002 to 2004, at least one calendar year of data is available for nine river sites (T1LB, T1MC, T1RB, T2LB, T2RB, T3MC, T4MC, T4RB, T5MC) and 13 riverbed sites (river sites plus 3MUS04, 5MDS04, 6MDN04, 7HS05). Several manual download sensors remain in place, and real-time sensors continue to transmit hourly data from the three real-time sites (T1LB, T2LB, T2MC). More detailed information regarding data availability is summarized in Appendix B and discussed by time period in Sections 5.1 through 5.6. 
Data are unavailable or missing for a variety of reasons. In some cases, as described in Section 4, we transferred sensors from one piezometer to another to collect higher-priority data. The most common sources of data loss were data logger malfunction and data logger loss. In numerous cases over the study period, data loggers could not be downloaded onsite and were returned to the manufacturer for data retrieval, with ultimate loss of data in most cases. We lost eight data loggers, of which three were found later on the riverbed. One Onset data logger, presumably washed from its piezometer during high river discharge, was ultimately found in Willapa Bay on the Pacific Ocean. Several data loggers were found at the bottom of their piezometers with the cable suspending them severed. One buoy system was vandalized, and other data logger losses were likely associated with vandalism as well. In some cases, there was evidence of damage to the piezometer, either from impact (e.g., by a passing boat) or from debris build up and associated increase in drag on the piezometer during high flow. Data logger loss was more likely in piezometers sealed by test plugs (rubber caps with an internal thumb screw securing the plug) or slip PVC caps, which were more prone to failure than threaded PVC caps. Thus far, we have experienced no problems with the real-time system, which was designed to withstand harsher conditions than the other deployments and to function for a longer duration.

\subsection{Through 2000}

Initial project installation began on October 22, so no complete October 1 through June 30 data sets are available for this year. Riverbed data are available for six sites beginning on either that date or November 10. Of these, 3MUS04 and 1LS04 are associated with chum salmon spawning. Combined mean (standard deviation [SD]) riverbed temperature for these sites was $11.1^{\circ} \mathrm{C}(1.98)$. Site $4 \mathrm{MUN04}$ is associated with fall Chinook spawning. Mean (SD) riverbed temperature for this site was $9.8^{\circ} \mathrm{C}(3.20)$. Bed temperatures in chum salmon spawning areas were more stable through the period than in the fall Chinook salmon spawning area; they were warmer through April and cooler from April through June (Figure 12). Daily bed temperatures were also more stable in chum salmon spawning areas than in the fall Chinook salmon area from December through February. No river temperature data were collected during 1999 through 2000.

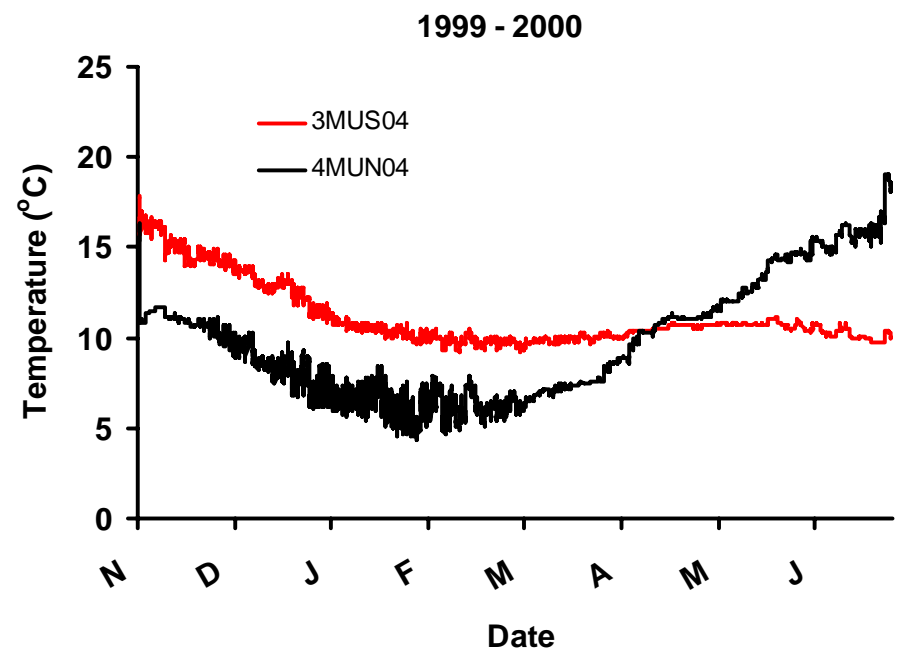

Figure 12. Bed Temperature Collected During 1999 through 2000 Within Chum (3MUS04) and Fall Chinook (4MUN04) Salmon Spawning Areas 


\subsection{Through 2001}

Complete bed temperature data sets were obtained at four locations (2LN04, 3MUS04, 5MDS04, and 6MDN04), as well as incomplete bed and river data for 4MUN04 (Figure 13) and several other sites not used for spawning. Mean (SD) bed temperatures for 3MUS04 and 4MUN04 for the period in which data are available for both sites (October 1 through April 12) were $13.3^{\circ} \mathrm{C}(2.96)$ and $7.1^{\circ} \mathrm{C}$ (3.55), respectively. Although bed temperatures were similar at the beginning of the period, they decreased significantly more at the fall Chinook salmon spawning site (4MUN04) than at the chum salmon spawning site (3MUS04) through March. Bed temperatures were also more stable at 3MUS04 across the period but generally more variable on a daily basis than at 4MUN04. Incomplete river temperature data sets are available for several sites (see Appendix B).

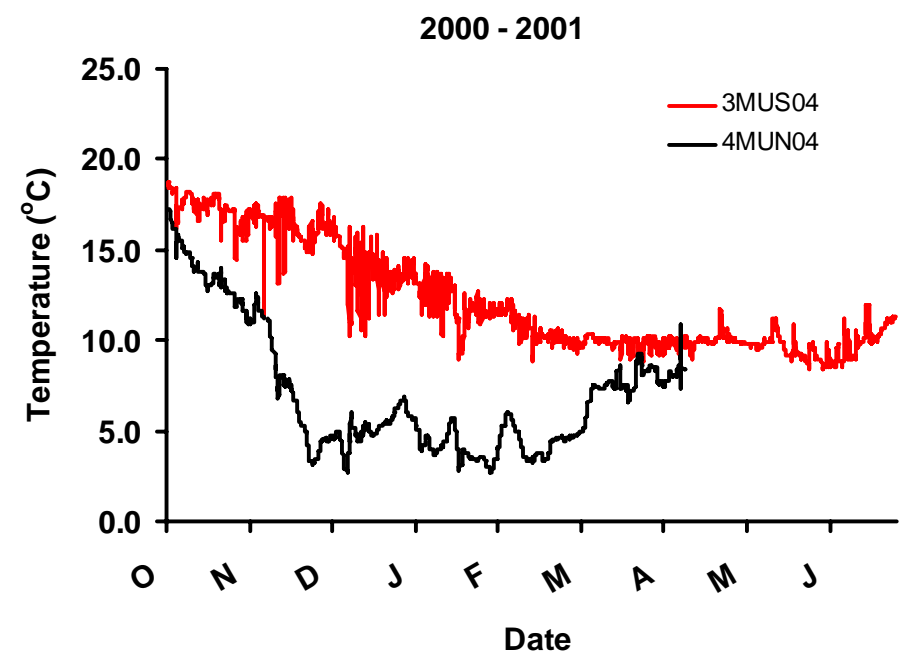

Figure 13. Bed Temperature Collected During 2000 through 2001 Within Chum (3MUS04) and Fall Chinook (4MUN04) Salmon Spawning Areas

\subsection{Through 2002}

Considerable data were collected during this period from previously installed piezometers as well as the additional T1-T4 piezometers installed on November 27, including paired river and riverbed data from several $\mathrm{T}$ transect piezometers. Complete data sets were obtained for ten riverbed and five river sites, including three sites for which both were obtained. Data for six sites in the channel north of Ives Island are presented in Figure 14, including the chum salmon spawning sites T1MC, T2RB, and 3MUS04 and the fall Chinook salmon site T4MC. For the period November 27 through June 30, combined mean (SD) bed temperatures for these (excluding 3MUS04) chum salmon spawning areas and the fall Chinook salmon spawning area were $9.8^{\circ} \mathrm{C}(1.44)$ and $8.7^{\circ} \mathrm{C}(3.60)$, respectively. Mean (SD) river temperature across the four sites in Figure 14 was $8.5^{\circ} \mathrm{C}(3.76)$. 

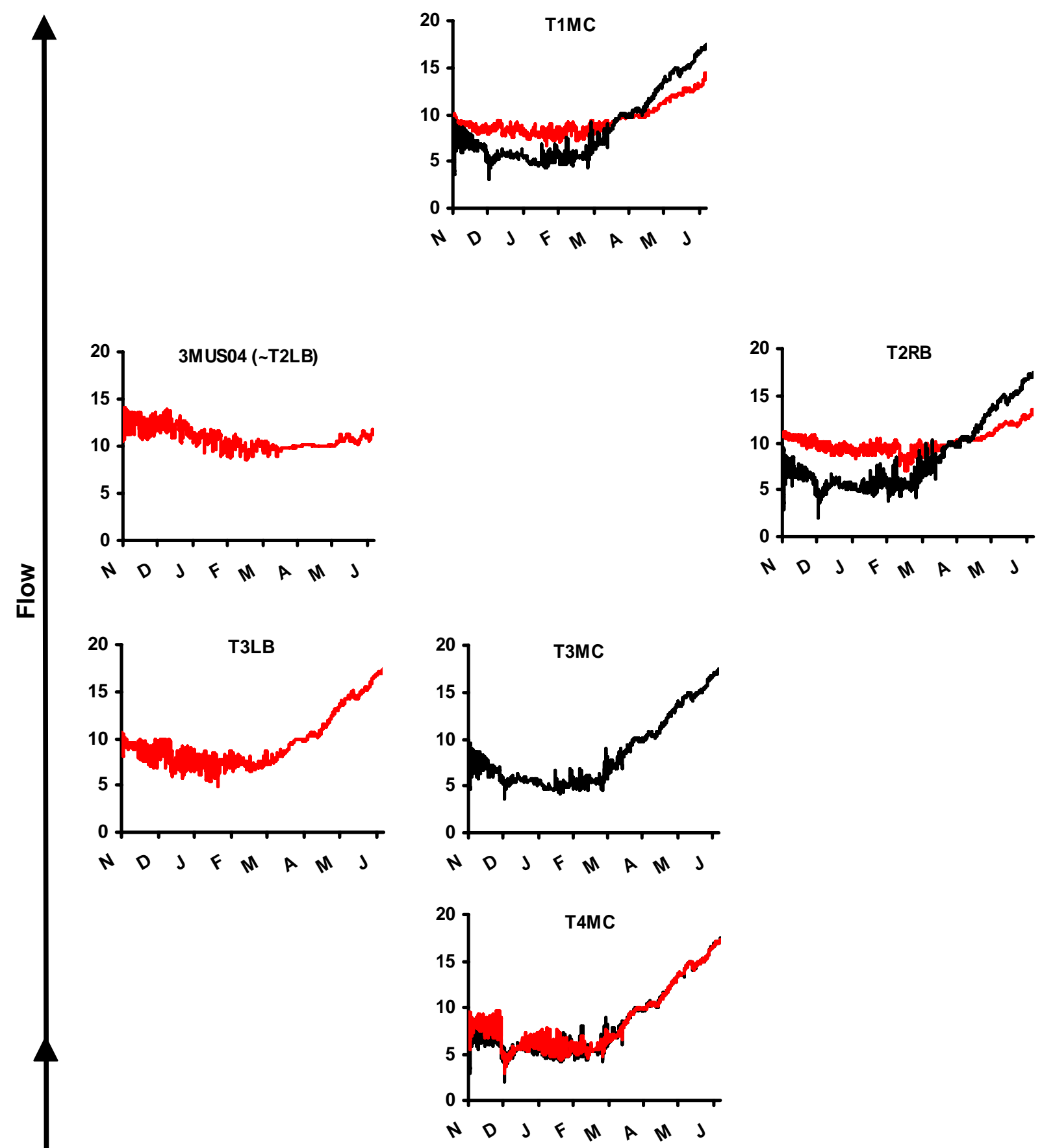

\section{Left bank (LB)}

Middle channel (MC)

Right bank (RB)

Figure 14. River (black line) and Riverbed (red line) Temperature, 2001 through 2002. Plots are arranged according to lateral and longitudinal site location within the channel north of Ives Island, with plots at the top furthest downstream and plots on the left along the left bank. In all plots, the $\mathrm{X}$ axis is date, from November 27, 2001 to June 30, 2002, and the Y axis is temperature $\left({ }^{\circ} \mathrm{C}\right)$. 
Examination of the summary statistics and data plots in Figure 14 reveals a pattern of surface/ subsurface interactions along this channel. Direction of flow between the bed and river is strongly upward from the subsurface at T2, and upward but less strongly so at T1. In contrast, flow is downward into the bed at T4. This pattern is reflected in the differing relationships between river and bed temperatures among these locations. At T1 and T2, bed temperatures are less variable over the period and on a daily basis than are river temperatures, reflecting the limited influence of river water on the bed environment. At T4, because river water flows into the bed, the temperature difference between river and bed water is reduced. Bed temperatures are more variable during the period and on a daily basis and reach lower fall temperatures and higher spring temperatures at T4 than at T1 or T2.

In fall 2001, in conjunction with the installation of the piezometers on transects T1 through T4, some temperature sensors from the 1999 through 2000 installation series were moved from the 1.2- to the 1.5-m piezometers, discontinuing data series at the shallower piezometers. Data from the 1999 through 2000 series and the transects installed in November 2001 are not directly comparable because temperature sensors are installed at different depths. Sensors installed during 1999 through 2000 were at 64 to $72 \mathrm{~cm}$, whereas the sensors installed in 2001 were at $30 \mathrm{~cm}$.

\subsection{Through 2003}

Considerable data at both river and bed locations were collected, including complete records for most sites during this period. Seven complete bed temperature records and four complete river records were collected (Figure 15), including three sites in spawning areas at which both bed and river data were collected (chum salmon, T1MC; fall Chinook salmon, T4MC and T4RB). Mean (SD) bed temperature for the chum salmon spawning area and combined mean (SD) bed temperature for the fall Chinook salmon spawning areas were $10.5^{\circ} \mathrm{C}(2.32)$ and $9.6^{\circ} \mathrm{C}$ (3.71), respectively. Combined mean (SD) river temperature across the four sites in Figure 16 was $9.7^{\circ} \mathrm{C}$ (3.86). As in previous years, bed temperature was more stable across the period and on a daily basis, particularly early in the period, at the T1MC site than river or bed temperature at the T4 sites. Bed temperature at the T4 sites largely reflected river temperature.

\subsection{Through 2004}

This period represents the most data-extensive period of the project. Complete or almost complete bed and river data sets were collected from nine and seven sites, respectively. Paired bed and river data sets are available at six sites. Although complete records are available at most sites, at the three real-time sites (T1LB, T2LB, and T2MC), some sensor records do not begin until October 16. Available data for eight sites in the channel north of Ives Island are presented in Figure 16. For the period October 16 through June 30, combined mean (SD) bed temperature for the five chum spawning areas (T1, T2) and mean (SD) for the fall Chinook salmon spawning area (T4RB) were $11.4^{\circ} \mathrm{C}(2.64)$ and $9.4^{\circ} \mathrm{C}(4.19)$, respectively. Mean (SD) river temperature across all seven sites in Figure 16 was $9.6^{\circ} \mathrm{C}$ (4.36). Patterns between bed and river and between chum and fall Chinook sites are similar to past years. At T1 and T2, bed temperatures are more stable than bed temperatures at $\mathrm{T} 4$ or river temperatures across the period and on a daily basis. There are exceptions, however. At T1RB and T2LB, bed temperatures are highly variable on a daily basis, particularly in the fall. 

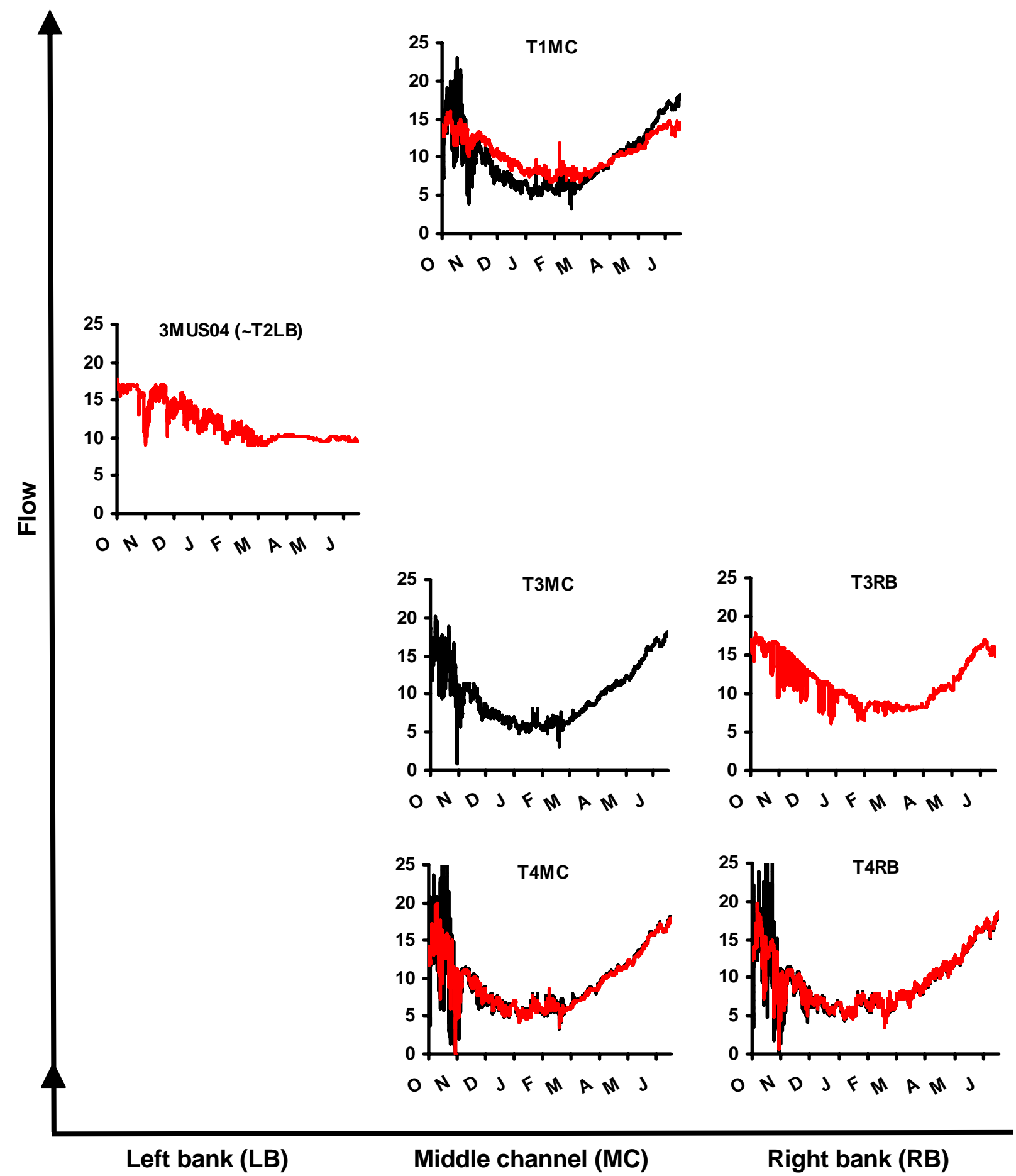

Figure 15. River (black line) and Riverbed (red line) Temperature, 2002 through 2003. Plots are arranged according to lateral and longitudinal site location within the channel north of Ives Island, with plots at the top furthest downstream and plots on the left along the left bank. In all plots, the $\mathrm{X}$ axis is date, from October 1, 2002 to June 30, 2003 and the $\mathrm{Y}$ axis is temperature $\left({ }^{\circ} \mathrm{C}\right)$. 

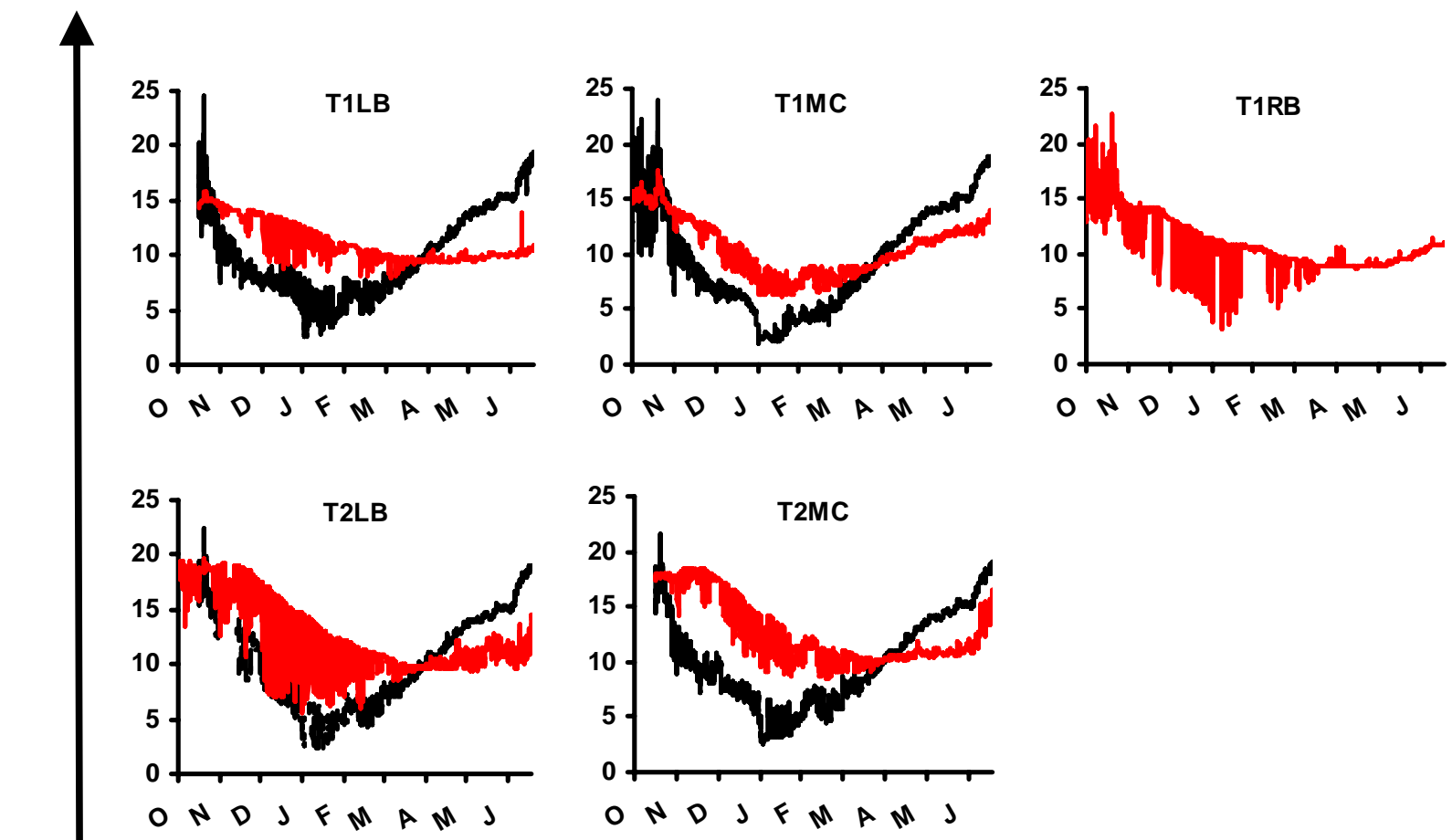

은
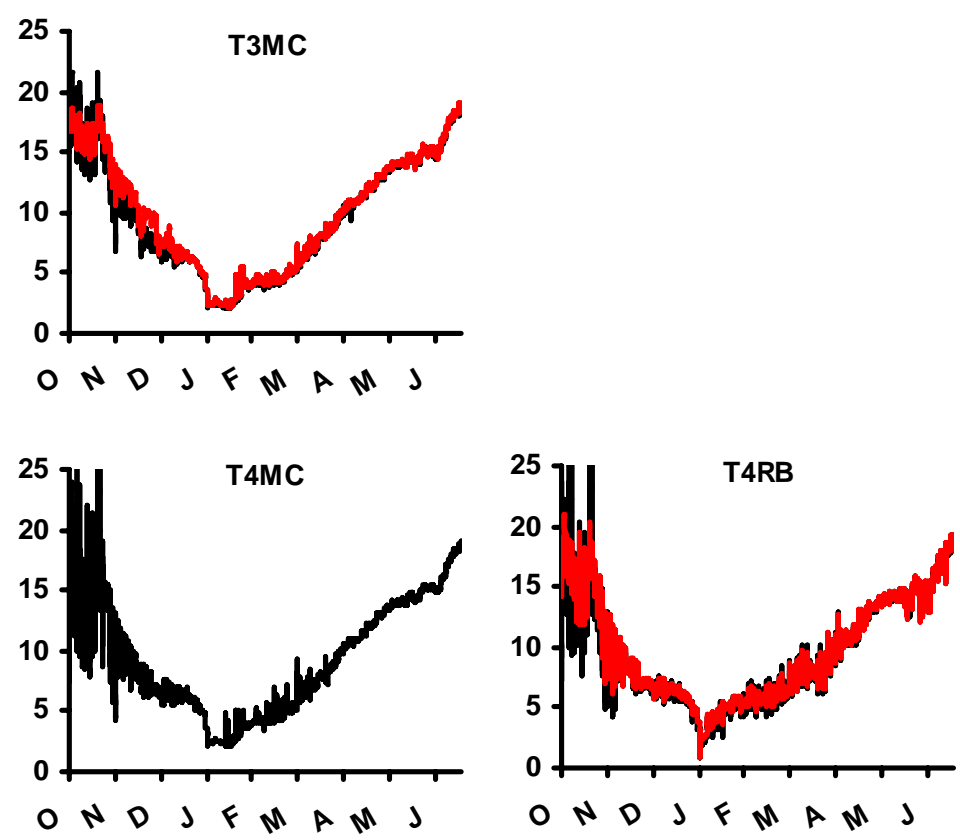

Left bank (LB)

Middle channel (MC)

Right bank

Figure 16. River (black line) and Riverbed (red line) Temperature, 2003 through 2004. Plots are arranged according to lateral and longitudinal site location within the channel north of Ives Island, with plots at the top furthest downstream and plots on the left along the left bank. In all plots, the $\mathrm{X}$ axis is date, from October 1, 2003 to June 30, 2004 and the $\mathrm{Y}$ axis is temperature $\left({ }^{\circ} \mathrm{C}\right)$. 


\subsection{Fall 2004}

The three real-time sensors (T1LB, T2LB, T2MC) and several manual data download piezometer sensors (T1MC [bed, river], T4MC [bed], T4RB [bed, river], T5MC [bed, river]) collected temperature data at chum salmon spawning areas through 2004 and remain in place. Data are summarized here only through December 2004 (Figure 17). Data from the real-time sensors for spring 2005 are available online from the FPC (see Section 4). Combined mean (SD) bed and river temperatures for these chum salmon spawning areas for fall 2004 were $15.6^{\circ} \mathrm{C}(2.64)$ and $11.9^{\circ} \mathrm{C}$ (3.14), respectively. The $\mathrm{T} 2$ sites show the same pattern of warmer bed than river temperatures during the fall that was seen in previous years. At T1LB, average bed and river temperatures appear similar through October, although bed temperatures are more stable. Although bed temperatures at all three sites are more stable than river temperatures on a daily basis through mid-November, they are more variable than river temperatures during December. This is particularly the case for T1LB. This pattern has not been seen in the data for previous years.
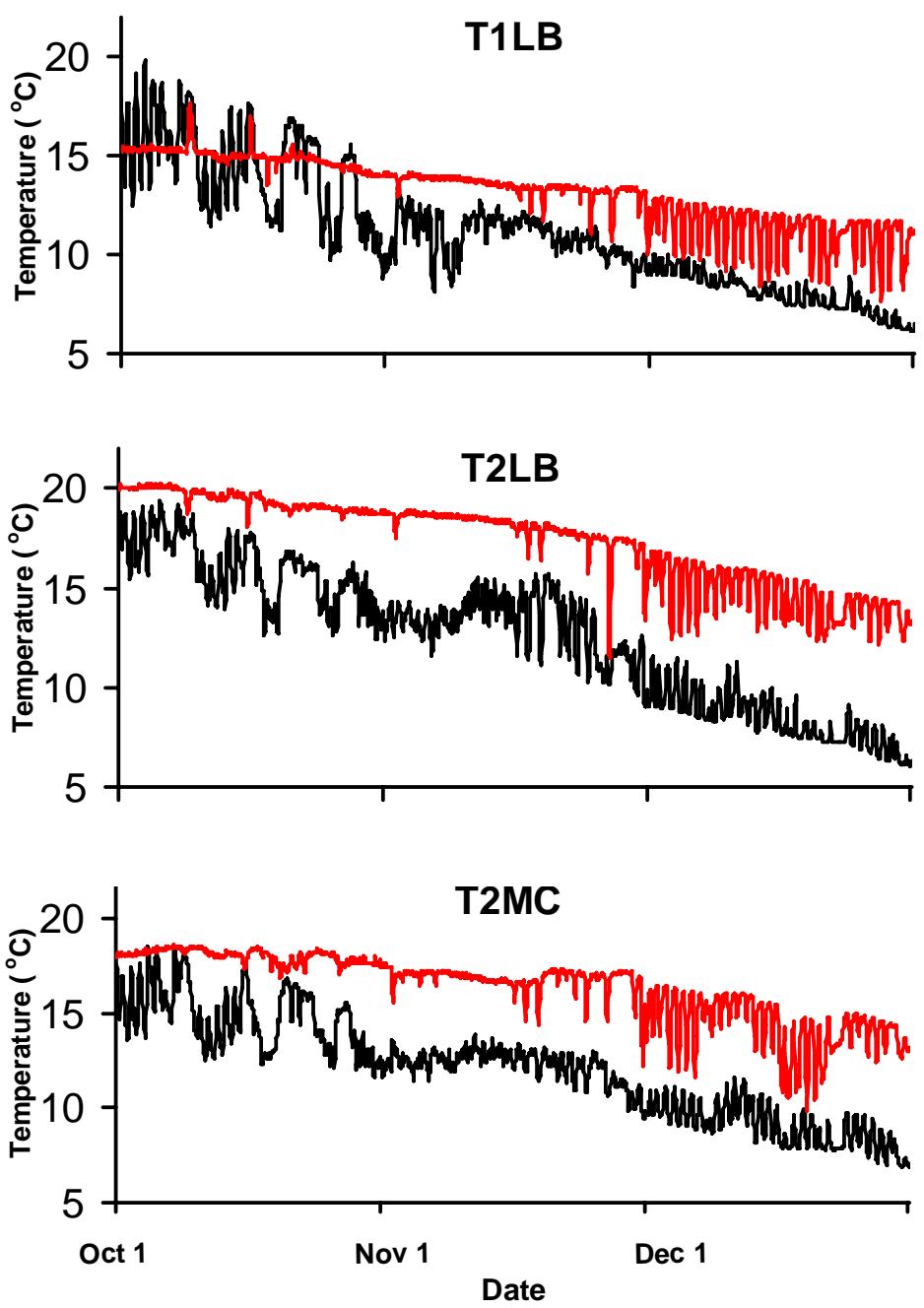

Figure 17. River (black) and Riverbed (red) Temperature During the Spawning Season, October 1 Through December 31, 2004, for Real-Time Sensors T1LB, T2LB, and T2MC 


\subsection{References}

Garland RD, KF Tiffan, DW Rondorf, J Skalicky, and DR Anglin. 2003. Evaluation of Fall Chinook and Chum Salmon Spawning Habitat Near Ives and Pierce Islands in the Columbia River - Progress Report 1999-2001. DOE/BP-00004701-1, Bonneville Power Administration, Portland, Oregon. Available at http://www.efw.bpa.gov/Publications/I00004701-1.pdf (October 13, 2005).

Geist DR, TP Hanrahan, EV Arntzen, GA McMichael, CJ Murray, and YJ Chien. 2002.

"Physicochemical Characteristics of the Hyporheic Zone Affect Redd Site Selection by Chum Salmon and Fall Chinook Salmon in the Columbia River." North American Journal of Fisheries Management 22:1077-1085.

Geist DR and DD Dauble. 1998. "Redd Site Selection and Spawning Habitat Use by Fall Chinook Salmon: The Importance of Geomorphic Features in Large Rivers.” Environmental Management 22:655-669.

Geist DR, MC Joy, DR Lee, and T Gonser. 1998. “A Method for Installing Piezometers in Large Cobble Bed Rivers.” Ground Water Monitoring and Remediation 28:78-82.

National Marine Fisheries Service. 1998. “Endangered and Threatened Species: Proposed Threatened Status and Designated Critical Habitat for Hood Canal Summer-Run Chum Salmon and Columbia River Chum Salmon.” Federal Register 63:11773-11795.

National Marine Fisheries Service. 1999. "Endangered and Threatened Species: Threatened Status of Two ESUs of Chum Salmon in Washington and Oregon.” Federal Register 64:14508-14517. 


\section{Appendix A}

\section{Temperature Sensor Location Information}




\section{Appendix A}

\section{Temperature Sensor Location Information}

\begin{tabular}{|c|c|c|c|c|}
\hline Name & Device $^{(a)}$ & $\Delta \mathrm{L}^{(\mathrm{b})}(\mathrm{cm})$ & $\mathrm{X}^{(\mathrm{c})}$ & $\mathrm{Y}^{(\mathrm{c})}$ \\
\hline 1LS04 & $\mathrm{OS} / \mathrm{T}$ & 77.0 & 578198 & 5053053 \\
\hline 1LS05 & OS & 60.5 & 578198 & 5053053 \\
\hline 2LN04 & OS & 63.0 & 578440 & 5053099 \\
\hline 3MUS04 & OS & 66.0 & 578207 & 5053038 \\
\hline 4MUN04 & $\mathrm{OS} / \mathrm{T}$ & 67.2 & 578300 & 5053093 \\
\hline 5MDS04 & OS & 69.2 & 577997 & 5052959 \\
\hline 6MDN04 & OS & 66.0 & 578085 & 5052991 \\
\hline 7HS04 & OS & 62.4 & 578267 & 5052923 \\
\hline 7HS05 & OS & 63.8 & 578267 & 5052923 \\
\hline T1LB & OS & 30.0 & 578126 & 5053019 \\
\hline T1LB & $\mathrm{PT}$ & 58.0 & 578121 & 5053018 \\
\hline T1MC & SOL & 30.0 & 578119 & 5053032 \\
\hline T1RB & OS & 30.0 & 578115 & 5053051 \\
\hline T2LB & OS & 31.0 & 578197 & 5053041 \\
\hline T2LB & $\mathrm{PT}$ & 58.4 & 578197 & 5053041 \\
\hline T2MC & OS & 31.0 & 578193 & 5053055 \\
\hline $\mathrm{T} 2 \mathrm{MC}$ & PT & 58.0 & 578193 & 5053055 \\
\hline $\mathrm{T} 2 \mathrm{RB}$ & OS & 30.0 & 578190 & 5053064 \\
\hline T3LB & OS & 30.0 & 578258 & 5053092 \\
\hline T3MC & SOL & 30.0 & 578254 & 5053096 \\
\hline T3RB & OS & 30.0 & 578250 & 5053101 \\
\hline T4LB & $\mathrm{T}$ & 35.5 & 578306 & 5053111 \\
\hline T4MC & SOL & 36.0 & 578298 & 5053121 \\
\hline T4RB & OS & $30.0^{(\mathrm{d})}$ & 578288 & 5053136 \\
\hline T5MC & SOL & $30.0^{(\mathrm{e})}$ & 578106 & 5052412 \\
\hline T6IL & $\mathrm{T}$ & 34.5 & 578113 & 5052944 \\
\hline
\end{tabular}

(a) $\mathrm{OS}=$ Onset Stowaway temperature data logger; $\mathrm{T}=$ Thermistor; $\mathrm{SOL}=$ Solinst temperature sensor; PT = Instrumentation NW PT2X temperature sensor.

(b) $\Delta \mathrm{L}=$ Depth of sensor below the riverbed.

(c) Horizontal coordinate system UTM Zone 10 North, Datum NAD 83.

(d) $\Delta \mathrm{L}$ changed to $38.0 \mathrm{~cm}$ on September 7, 2003.

(e) $\Delta \mathrm{L}$ changed to $24.2 \mathrm{~cm}$ on October 10, 2002. 


\section{Appendix B}

Summary of Temperature Data Collected Downstream from Bonneville Dam in the Ives Island Area by Pacific Northwest National Laboratory, 1999-2004 


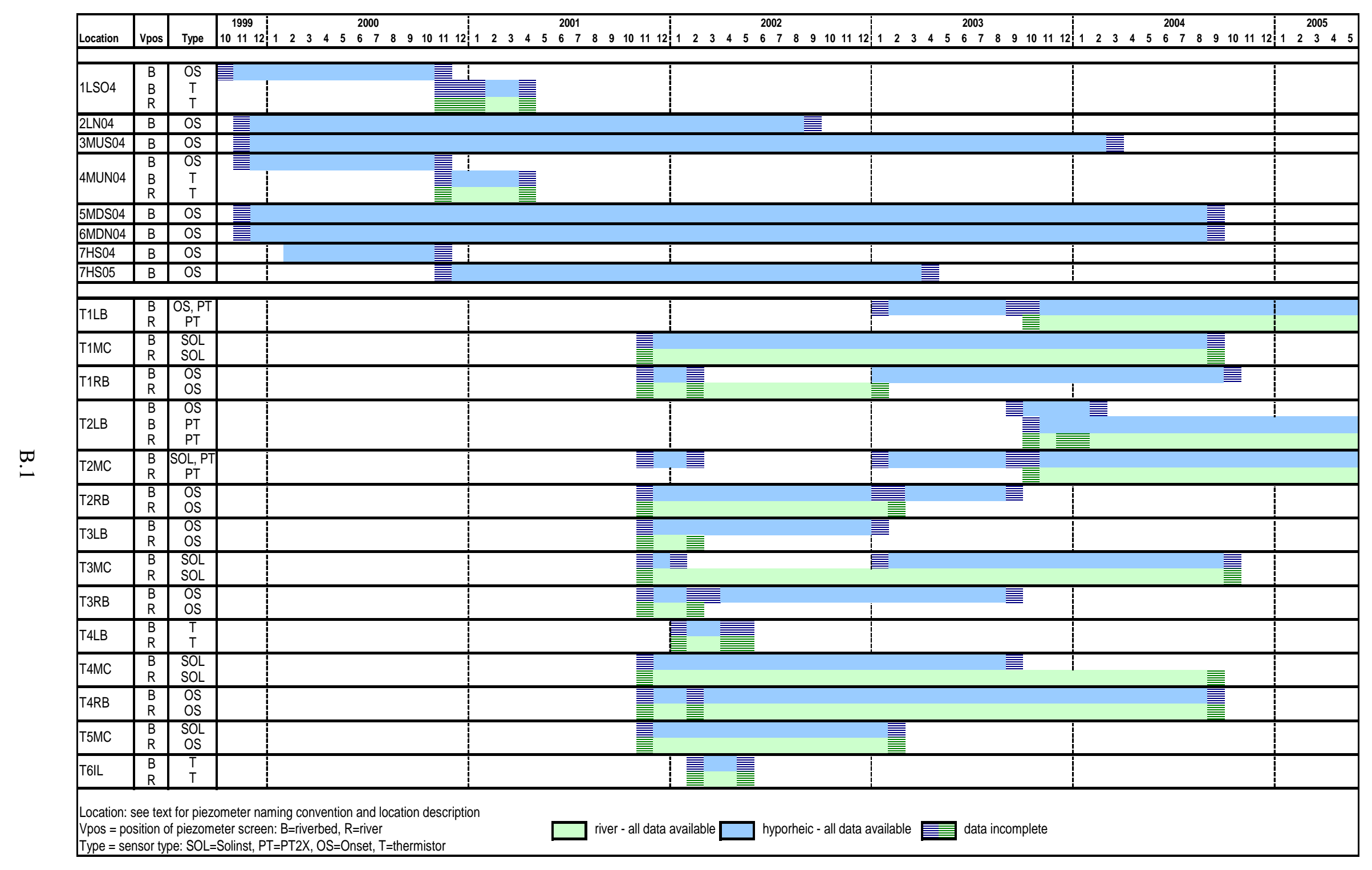


Appendix C

\section{Temperature Data Compendium}




\section{Appendix C}

\section{Temperature Data Compendium}

Click here to open Appendix C Temperature Data Compendium (1.85MB pdf file) 